\title{
ASPECTS PISCICOLES DU FLEUVE ARGENS (VAR)
}

\author{
A. KIENER*, A. DELIZE* et P. BELKIOR**
}

\section{INTRODUCTION}

I - etude GENERALE du COURS D'EAU ET BASSIN VERSANT (Fig. 1 à 7)

I. 1 : Topographie du Bassin versant. L'Argens actuel et l'ancien estuaire de StAygulf (fig. 1 à 4 ).

1. 2 : Cas particuliers de 1'. Eau salée * et de la source de "La Foux.

I. 3 : Profils en long de l'Argens et de quelques affluents (fig. 5). Régime hydrologique (fig. 6).

1. 4 : Aperçu géologique du bassin versant (fig. 7).

1. 5 : Végétation du bassin versant.

II - APERÇU DU MILIEU PHYSICO-CHIMIQUE (Fig. 8 et 9)

Composition chimique des eaux. Cas particuliers de $l^{\prime}$ : Eau salée et de la source de : La Foux*. Zone saumâtre de l'estuaire et zone Villepey-St-Aygulf.

III - FAune IChTYOLOGiQue (Fig. 10 et 11)

III. 1 : Espèces d'eau douce.

HII. 2 : Espèces euryhalines.

III. 3 : Zones piscicoles (eaux douces) et estuaire. Cas de l'étang de Villepey et de la lagune de St-Aygulf.

III. 4 : Pêche.

IV - PROBLEME DES GRAVIERES - SABLIERES

\section{CONCLUSION}

\section{BIBLIOGRAPHIE}

\section{INTRODUCTION}

Le fleuve côtier ARGENS présente un grand intérêt à la fois par la variété de ses espèces ichtyologiques, la diversité de ses biotopes, la richesse piscicole de ses affluents ainsi que par l'attrait touristique de ses sites : cascades naturelles, perte d'Entraigues (près de Vidauban), seuils, gorges (Vallon Sourn), berges généralement facilement accessibles, retenue de Carcès aménagée au confluent du Caramy et de l'Issole...

Portant sur un ensemble de $2805 \mathrm{~km}^{2}$, le bassin versant occupe plus de la moitié du département du Var (fig. 1) et il est quatre fois plus important que celui du deuxième cours d'eau du département, le Gapeau, qui lui est contigu au Sud. Les autres rivières voisines, de quelque importance, sont limitrophes au département : le Verdon au Nord et la Siagne à l'Est.

Signalons, dès à présent, plusieurs curiosités qui en augmentent les intérêts scientifiques et touristiques :

- les sources de l" Eau salée - (en amont de Barjols) et de la * Foux * (Draguignan), toutes deux saumâtres, avec des salinités respectivement voisines de 5 et $2 \mathrm{gr} / \mathrm{l}$,

- le site de la perte karstique de l'Argens (à côté du barrage EDF d'EntraiguesVidauban), avec ses petites grottes et ses grosses stalactites,

- la résurgence du * Bouilli-doux . (un peu en amont de Châteauvert),

- I'ancien estuaire de l'Argens qui, formé par la lagune saumâtre de St-Aygulf, a été abandonné par le fleuve qui a porté son embouchure un peu plus au Nord, plus près de Fréjus. Ce transfert a probablement permis, lors d'une grande crue, la jonction avec le Reyran, jadis indépendant et se jetant dans l'ancien golfe de St-Raphaël, progressivement comblé.

\footnotetext{
- Ingénieur en Chef du G.R.E.F. Section Qualité des eaux, Pêche et Pisciculture. Groupement d'Aix-enProvence CEMAGREF.

“-Ancien et nouveau gardes-chefs du Conseil Supérieur de la Pêche, Fédération des A.P.P. dü. Var. Brignoles (Var).
} 


\section{PRINCIPAUX COURS D'EAU \\ $D \cup \vee A R$}

Fig. 1

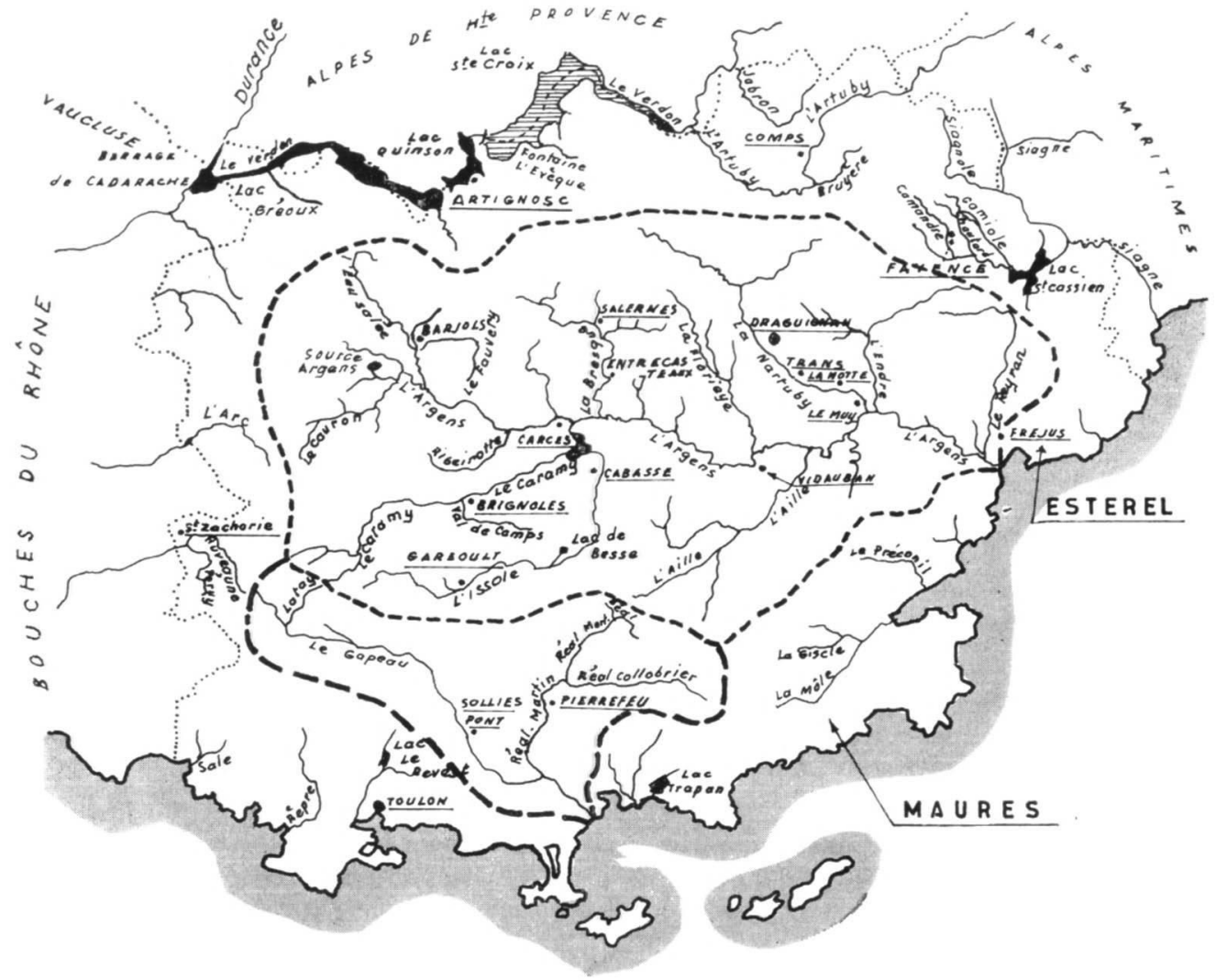

Cette étude est essentiellement piscicole et il faut signaler le travail en cours poursuivi par la section * Qualité des Eaux * du C.E.M.A.G.R.E.F. du Groupement d'Aix-en-Provence sur les biocénoses et les problèmes de pollution de l'ensemble Argens-Gapeau, ce dernier cours d'eau ayant déjà fait l'objet d'une étude par l'un de nous (A. KIENER - 1970 avec 3 . OLLIER).

\section{CHAPITRE ।}

\section{ETUDE GENERALE DU COURS D'EAU ET BASSIN VERSANT}

\section{1. - TOPOGRAPHIE DU BASSIN VERSANT. L'ARGENS ACTUEL ET L'ANCIEN ES- TUAIRE DE ST-AYGULF.}

L'ensemble de la rivière et de ses affluents a été précisé par les figures 2 et 3 . L'Argens a déjà fait l'objet de plusieurs travaux parmi lesquels il faut citer celui du S.R.A.E. Inséré entre les vastes formations calcaires du Verdon (au Nord, avec des sommets dépassant $1000 \mathrm{~m})$, les massifs montagneux du Mourre d'Agnis $(915 \mathrm{~m})$ et du Pilon de StClément (705 m au Sud-Ouest) et le massif cristallin des Maures et de l'Estérel au Sud et à l'Est, ce vaste bassin versant, d'altitude moyenne voisine de $300 \mathrm{~m}$, est séparé à l'Ouest du bassin de l'Arc par une ligne de crête de faible altitude. La source du fleuve se trouve 


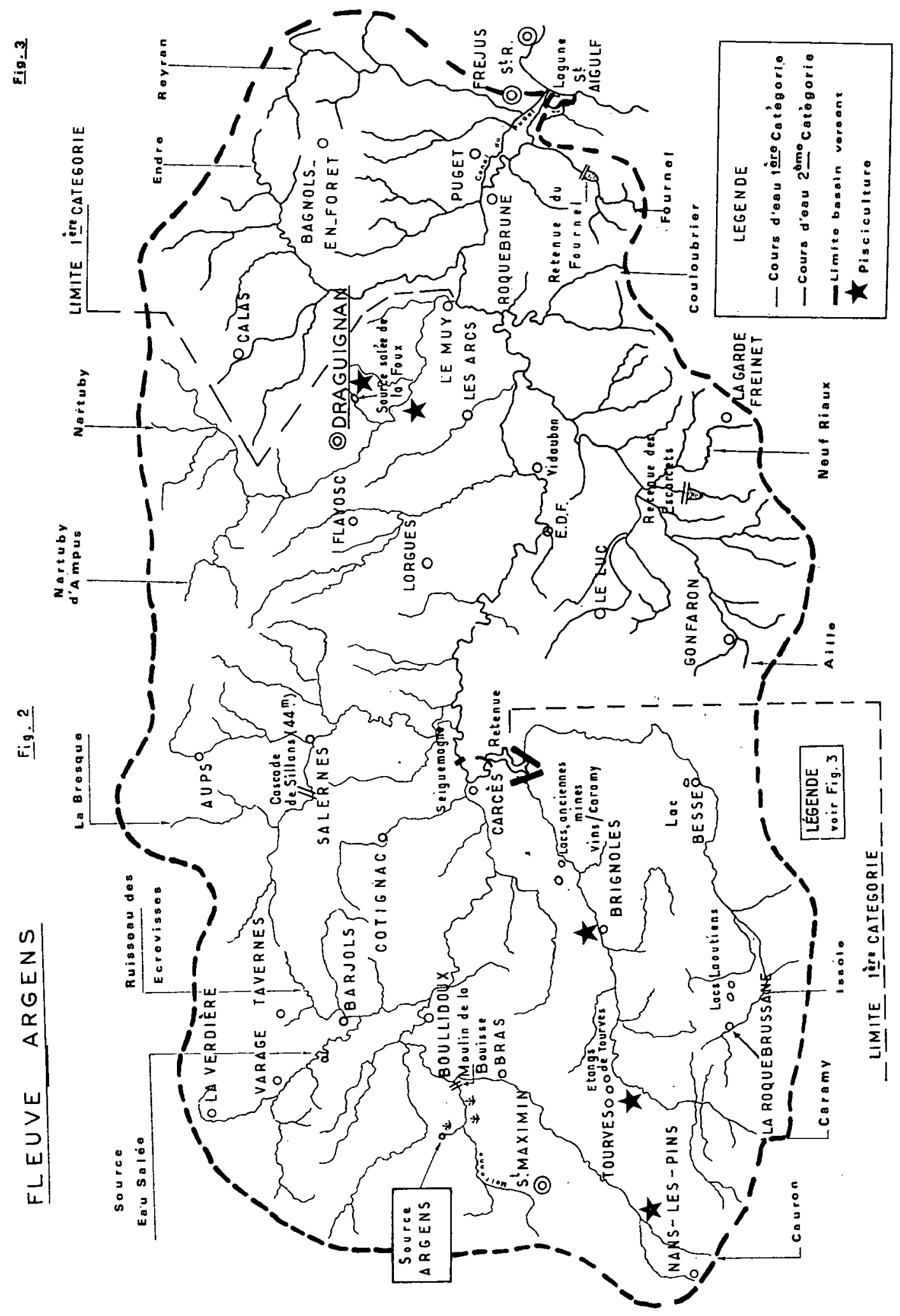


dans la commune de Seillons-Source d'Argens, en bordure de la route départementale 500 , à l'altitude $269 \mathrm{~m}$.

La rivière a $114 \mathrm{~km}$ de long, avec une pente moyenne relativement faible de $2,35 \%$ o et des débits moyens voisins de $11,5 \mathrm{~m}^{3} / \mathrm{sec}$. à Entraigues (usine, période de 1931-1956) et $35 \mathrm{~m}^{3} / \mathrm{sec}$. en aval près de Roquebrune. Les principaux affluents ont les caractéristiques suivantes, par importance décroissante (fig. 2 et 3 ) :

\section{AFFLUENTS}

Caramy - R.D. (avec Issole)

Aille - R.D.

Nartuby-R.G. (avec Nartuby d'Ampus)

Endre-R.G.

Eau salée - (R.G. (avec ruisseau de Varrage)

Bresque - R G.

Cauron - R.G.

(de temps en temps partiellement à sec)

\section{BASSIN VERSANT}

$479 \mathrm{~km}^{2}$
284
218
189
163
296
148

LONGUEUR
$\begin{aligned} & 34 \mathrm{~km} \\ & 28 \\ & 33 \\ & 23 \\ & 22 \\ & 32 \\ & 27\end{aligned}$

sans oublier les affluents secondaires de Font Taillade et Rigouards en amont (R.G.), Cassolle, Floriège (R.G.) grossissant l'Argens moyen et, en aval, le Ronflon, le Blavet et le Reyran en R.G., le Couloubrier et le Fournel en R.D.

En plus du cours d'eau proprement dit, de ses affluents, de la retenue de Carcès, il faut signaler quelques petits plans d'eau d'importance très secondaire :

- le petit * lac × de Besse, ancien étang surélevé par un petit barrage, à Besse sur issole,

- à titre de curiosité, deux petits plans d'eau appelés "lacs laoutiens », à la Roquebrussanne,

- deux petits étangs près de Tourves, au voisinage du Caramy,

- en bordure du Caramy, deux petits plans d'eau occupant deux anciennes mines de bauxite à Vins-sur-Caramy.

En étudiant la zone d'estuaire (au sens éthymologique du mot, soumis à l'influence de la mer) et la topographie des environs de l'embouchure actuelle, l'on se rend compte que dans la zone plate du littoral, entre St-Aygulf et Fréjus-plage, l'ancienne embouchure de l'Argens devait être, en réalité, la petite lagune de St-Aygulf, aux eaux et biocénoses saumâtres, prolongée dans, l'arrière pays par les étangs marécageux de Villepey où venait aboutir l'Argens (fig. 4).

Ce dernier a été relié au Reyran par des aménagements récents. Au voisinage immédiat Sud de l'embouchure, un ancien bras mort, agrandi par d'anciennes carrières de sable, abrite également des eaux saumâtres avec une faune mixte portant sur des éléments dulcicoles et des éléments euryhalins (qui supportent différents degrés de salinité).

\section{2. - CAS PARTICULIERS DE L'EAU SALEe ET DE LA SOURCE DE LA FOUX.}

La rivière dite a Eau salèe . est en réalité constituée par le ruisseau de Varrages recevant, à $4 \mathrm{~km}$ environ en amont du pont de Barjols, les eaux d'une source salée qui sort à quelques dizaines de mètres de la rivière et qui s'y jette actuellement par l'intermédiaire d'un petit canal aménagé. La salinité de la source est voisine de $5 \mathrm{~g} / \mathrm{litre}$ et le ruisseau, dès lors dénommé "eau salée », est grossi, au Sud de Barjols, par le ruisseau des écrevisses, recevant lui-même le ruisseau de Pontevès et le Fauvery. Nous verrons, par la suite, l'origine de ces eaux salées.

Une autre source, relativement moins salée $(2 \mathrm{~g} / 1)$, mais beaucoup plus importante, quant à son débit, est celle de la Foux, à deux kilomètres au Sud-Est de Draquignan. Elle est utilisée pour un élevage important de truites arc-en-ciel.

\section{3. - PROFILS EN LONG DE L'ARGENS ET DE QUELQUES AFFLUENTS. REGIME HYDROLOGIQUE.}

Les profils déjà définis par l'Institut Géographique National et par MASUREL (1964) ont été reproduits sur la figure 5 en y séparant les affluents de la rive gauche de ceux de la rive droite. Les chiffres d'altitude (notamment ceux des sources des deux Nartuby) permettent de mettre en relief combien la ligne de crête Nord de la bordure préalpine est souvent plus haute que les autres limites du bassin versant.

La pente de l'Argens, relativement faible dans son ensemble $(0,235 \%)$, présente de fortes inégalités tout au long de son cours et celles-ci peuvent être schématisées comme suit :

- très court tronçion, de la source à $300 \mathrm{~m}$ en aval, à cheval sur la route N. 500 . avec une pente de $0,3 \%$;

- paradoxalement le cours d'eau a ensuite une pente très faible $(0,14 \%)$ dans le tronçon aval jusqu'au moulin de la Bouysse, aux chutes dites du Tombe- 


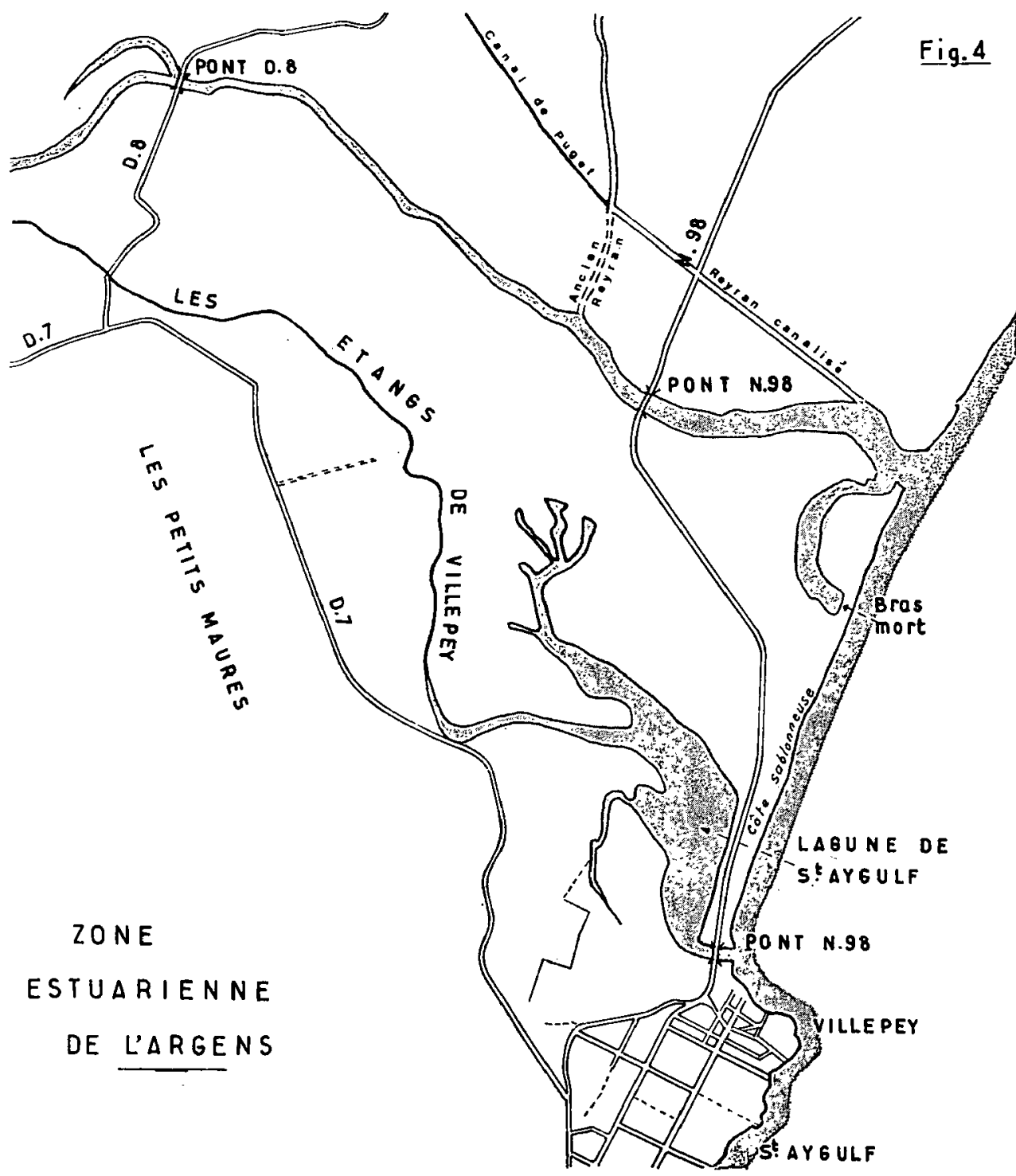

reau qui sont juste avant le confluent de l'Argens (ayant déjà reçu la Meironne) avec le Cauron.

Cette zone calme est caractérisée par une vallée marécargeuse, au cours de la rivière très lent et, comme nous le verrons, marquée sur le plan piscicole par une population de cyprinidés. C"est un tronçon atypique dans la zonation piscicole habituelle.

Après la chute du Tombereau, la pente redevient plus forte. Marqué par la présence de plusieurs seuils et situé en Provence calcaire (jusqu'à la perte de l'Argens à Entraigues, peu après l'importante source des Avens, près du barrage EDF), le cours d'eau présente une pente moyenne de $0,3 \%$. Par la suite, en courte zone de dépression permienne de $\mathrm{Vi-}$ dauban, la pente redevient plus faible $(0,19 \%)$, puis augmente très légèrement à partir de l'entrée du massif cristallin jusqu'à la zone amont de l'estuaire marquée par le petit barrage de Roquebrune-sur-Argens reconstitué (après sa rupture par des crues).

Dans la plaine alluviale de Fréjus, superposée à un ancien golf comblé, la pente redevient faible; c'est la zone située en aval du pont de la route dépaitementale 8 . L'influence de la marée est surtout sensible à l'aval de la RN 98 malgré une marée particulièrement faible en Méditerrannée, avec une amplitude d'environ $25 \mathrm{~cm}$. 

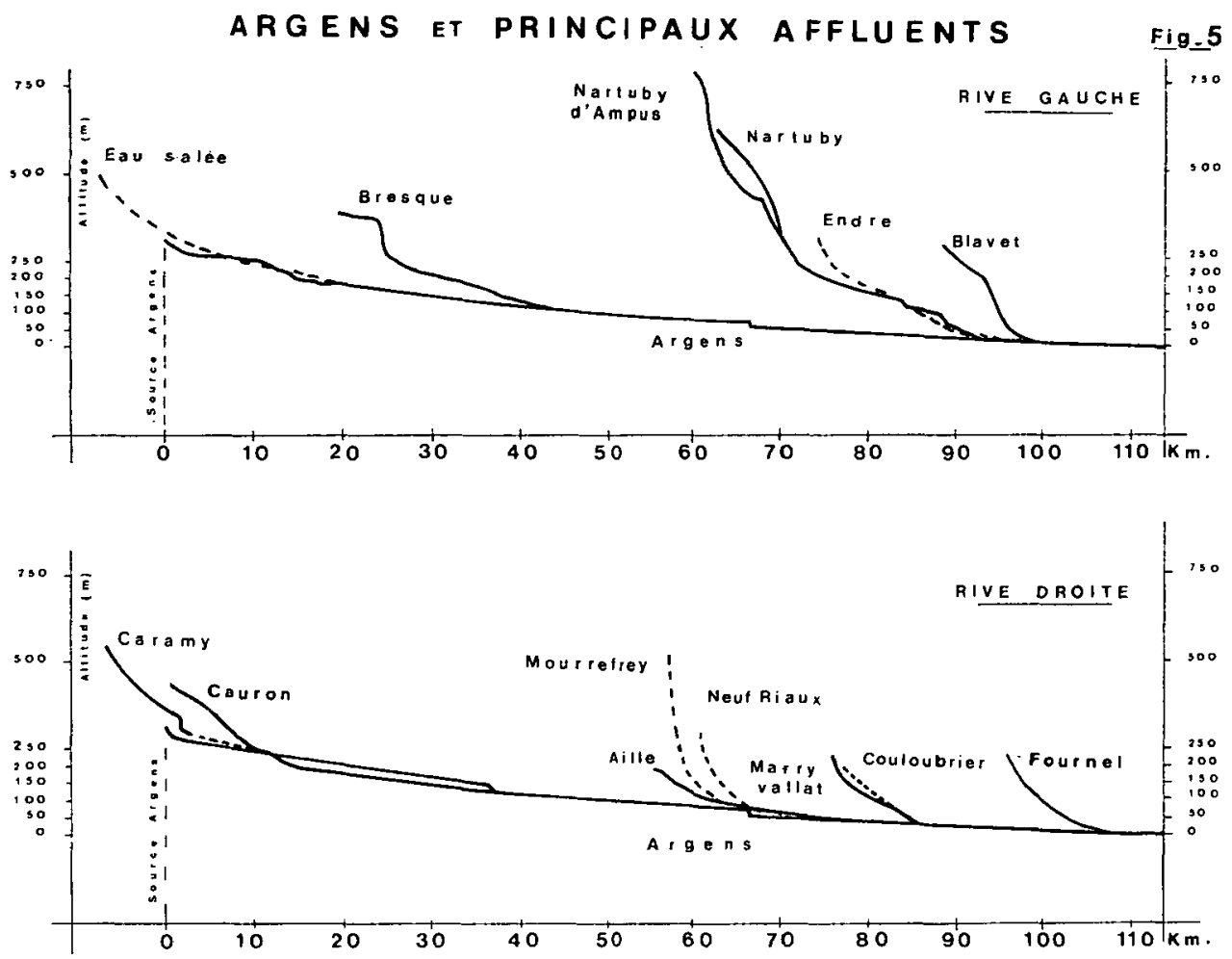

Comme tous les fleuves côtiers méditerranéens, l'Argens est marqué à la fois par les étiages estivaux sévères (tableau l, fig. 6) et par de très fortes variations de débits d'une année à l'autre (caractéristique du Midi-Méditerranéen avec de grandes variations des pluviosités annuelles, bien plus larges que pour le facteur a température $\cdot$, beaucoup plus stable). L'on a pu enregistrer, à Entraigues (usine EDF), au cours de la période 1931-1960, plusieurs étiages marqués de $1,75 \mathrm{~m}^{3} / \mathrm{sec}$. et une crue journalière de $183 \mathrm{~m}^{3} / \mathrm{sec}$. avec un débit moyen de $11,4 \mathrm{~m}^{3} / \mathrm{sec}$., ce dernier ayant atteint 15,1 au cours des trois années 1957-1960. L'été 1967, anormalement sec dans le Midi-Méditerranéen, a été marqué par un ètiage particulièrement sévère.

Le barrage de Carcès, aménagé au confluent du Caramy et de l'Issole pour alimenter en eau la région de Toulon, peut influencer le débit de l'Argens en aval de Carcès, zone marquée par les grandes cascades aval de la retenue et par la chute de Seiguemagne sur l'Argens.

\section{4. - APERÇU GEOLOGIQUE DU BASSIN VERSANT.}

Partagé entre la Provence calcaire, qui occupe la plus grande partie du bassin versant du fleuve, et la Provence cristalline, à l'Est, formée par le Massif côtier des Maures et de l'Estérel, l'Argens proprement dit est à cheval entre ces différentes formations. Il ne rentre pas dans le cadre de ce travail de faire l'étude détaillée de la géologie de la région (carte schématique de la figure 7), mais rappelons trois aspects qui marquent certaines particularités que nous avons déjà signalées :

- l'abondance des formations karstiques,

- l'influence des couches triassiques sur la minéralisation de certaines sources,

- I'influence des formations cristallines sur la nature des eaux des affluents du bas-Argens.

En ce qui concerne les formations karstiques, celles-ci sont à l'origine :

- de très nombreuses cascades, à la fois sur le haut et le moyen Argens (Tombereau, plusieurs seuils, Seiguemagne, Vidauban) et sur les divers affluents, notamment à la sortie de la retenue de Carcès,

- de résurgences importantes, telles que le Bouillidoux, la source des Avens (usine EDF) à Entraigues,

- de la gorge du vallon Sourn, entre Châteauvert et Correns, 


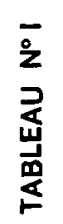

\begin{tabular}{|c|c|c|c|}
\hline 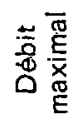 & 응 ్ㅗㅇ & 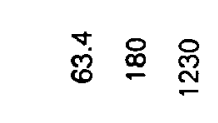 & \\
\hline 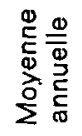 & 员 & 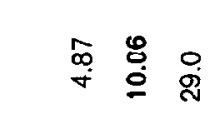 & $\stackrel{ \pm}{=}$ \\
\hline 0 & $\stackrel{\circ}{\circ} \stackrel{0}{\circ} \stackrel{10}{\circ}$ & 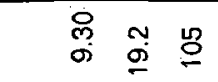 & $\stackrel{\sim}{\infty}$ \\
\hline$z$ & 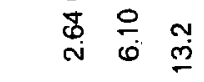 & 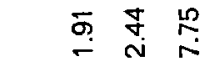 & $\stackrel{N}{ \pm}$ \\
\hline 0 & 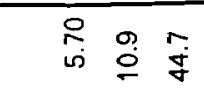 & 永 & 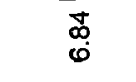 \\
\hline$\infty$ & 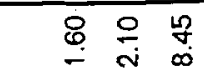 & 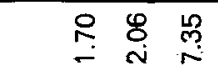 & $\underset{m}{m}$ \\
\hline$\ll$ & 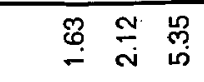 & 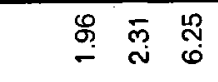 & $\underset{\sim}{\tilde{n}}$ \\
\hline$\neg$ & 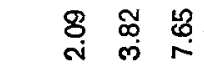 & 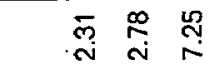 & $\stackrel{9}{q}$ \\
\hline- & 岕 & 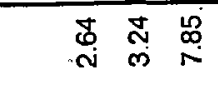 & $\stackrel{\text { 㝵 }}{\sim}$ \\
\hline$\Sigma$ & 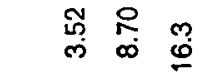 & 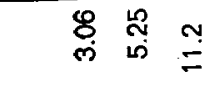 & $\stackrel{m}{\mathscr{m}}$ \\
\hline$\ll$ & 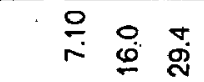 & 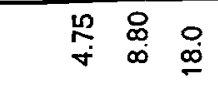 & $\stackrel{\mathscr{I}}{\dot{I}}$ \\
\hline$\Sigma$ & 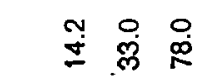 & 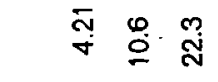 & Lִ \\
\hline$u$ & 品 & 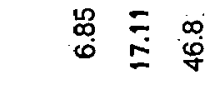 & 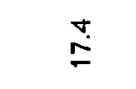 \\
\hline$\neg$ & 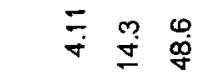 & 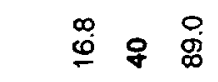 & $\stackrel{\leftrightarrow}{\mathscr{O}}$ \\
\hline$\frac{\mathscr{C}}{Z}$ & 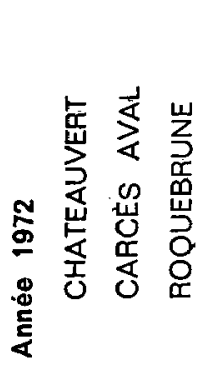 & 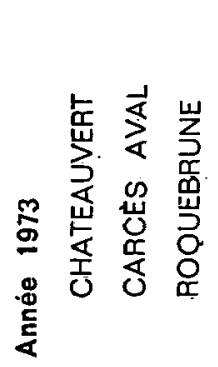 & 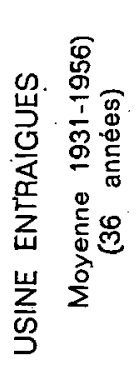 \\
\hline
\end{tabular}



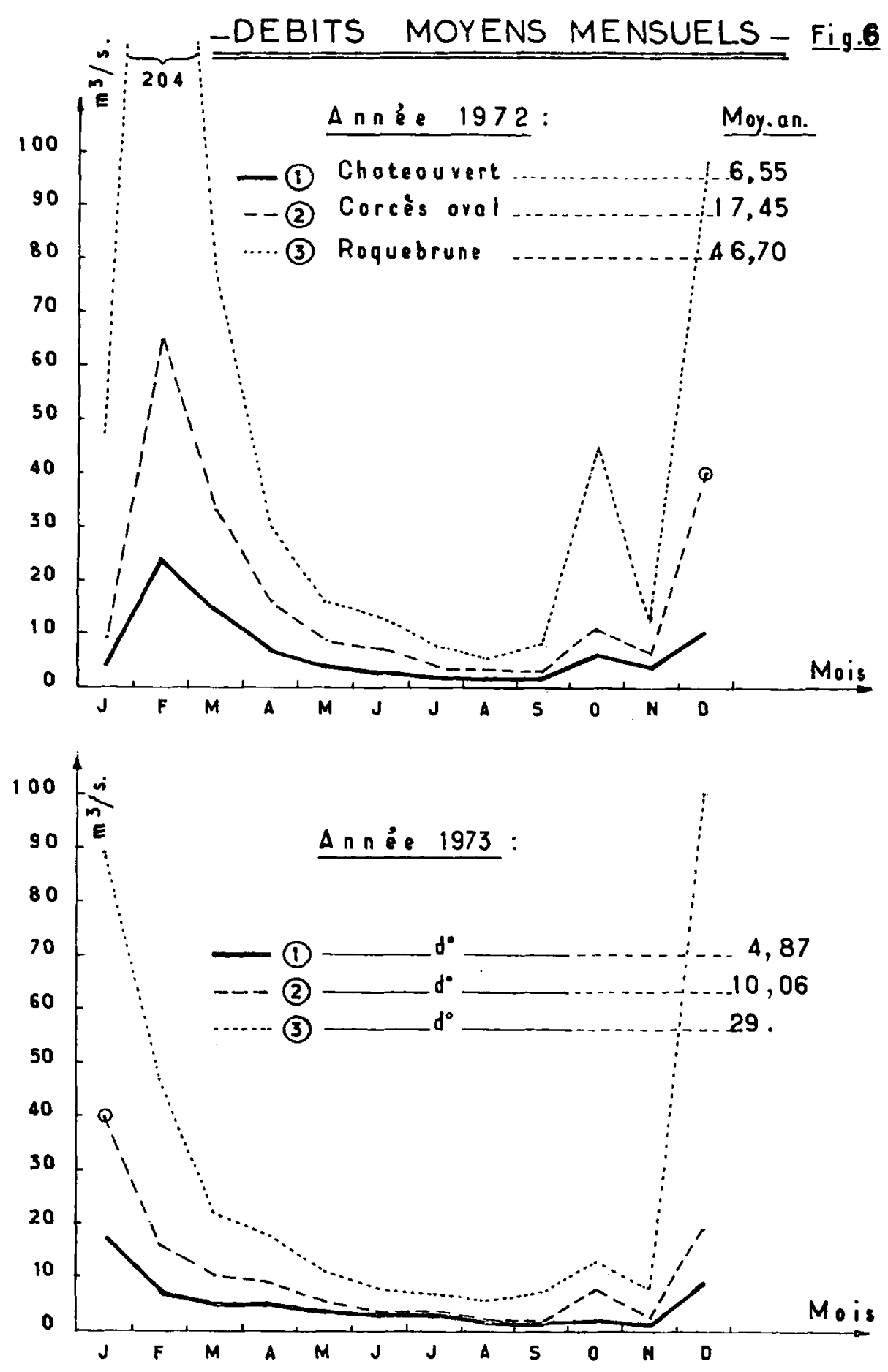


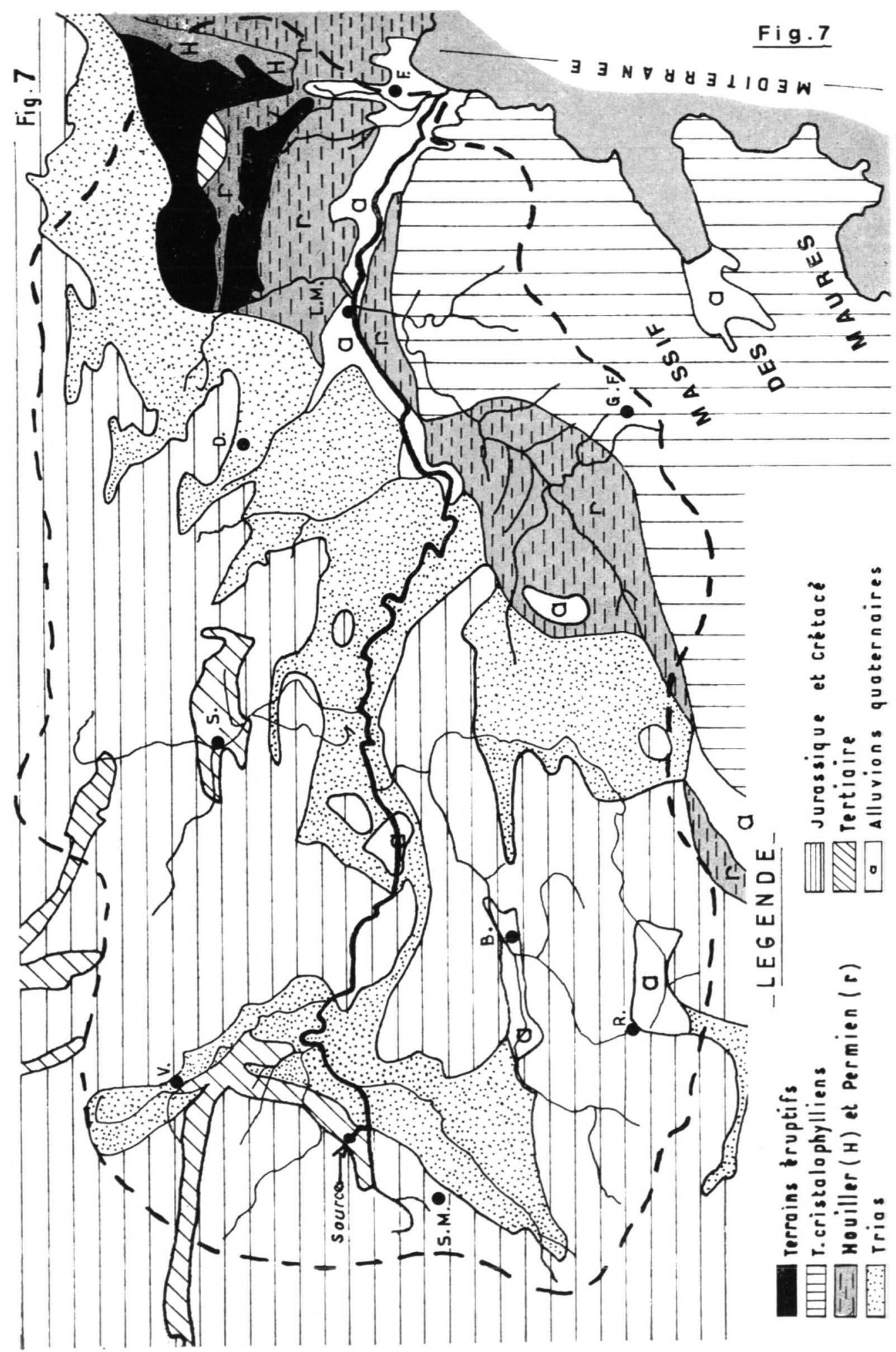


- de la rupture de pente d'Entraigues, zone où le cours d'eau entaillant une grosse masse de tufs, se divise en plusieurs bras, les uns se terminant en chutes, un seul, mais important, devenant souterrain (sur une courte distance il est vrai), la voûte étant percée d'un grand regard où l'on peut admirer de grosses stalactites. Le paysage est particulièrement beau et curieux, avec quelques cavités karstiques (présence d'une ancienne chapelle ayant servi sous la Révolution) dans les parois du très court canyon au fond duquel il est facile de descendre. De plus nous verrons que ce tronçon est riche en truites.

\section{5. - VEgetation dU bassin VERSANT.}

La nature géologique du bassin versant influe également, et de façon très nette, sur la végétation et les paysages nettement individualisés par certaines essences à affinités soit calcicoles, soit silicicoles (réf. MOLINIER R. et R., 1971, ROLL et JACAMON, 1968) : a) dans la grande zone calcaire Ouest, partie intégrante de la "Provence calcaire *, la végétation est très variée et au milieu d'une vaste * garrigue •, la végétation arborée est essentiellement à base :

- de chêne vert, sorbier, prunellier, érable... avec un peu de ripisylve le long des cours d'eau (saules, aulnes, peupliers) et chêne blanc en altitude,

- de pins (alep en basse altitude, maritime mésogéen et sylvestre en altitude...) et de génevrier.

b) Dans la zone cristalline, en majeure partie occupée par le chêne-liège et un peu par le chêne vert, les pins sont également très abondants : maritime, pignon, alep et l'on trouve un peu partout, disséminé au milieu du maquis $*$, une espèce caractéristique des sols. siliceux: l'arbousier.

Enfin signalons une autre espèce silicicole, également spécifique des zones cristallines, le châtaignier formant, çà et là, des petits massifs aménagés (espèce non spontanée).

Dans son ensemble, quoique la végétation ait été très attaquée par les défrichements ou dégradée par les feux, il reste encore dans le Var pas mal de couverture végétale et celle-ci a un rôle indéniable sur le ruissellement des eaux et la régulation des cours d'eau. La presque totalité des terres cultivées est occupée par des vignes.

\section{CHAPITRE \|}

\section{APERÇU DU MILIEU PHYSICO-CHIMIQUE}

- Composition chimique des eaux de l'Argens (tableau II, fig. 8 et 9).

- Cas particulier de l's Eau salée - et de \& La Foux - (tableaux III et III bis, fig. 8 et 9).

- La zone saumâtre de l'estuaire et la zone Villepey - St-Aygulf.

Nous n'étudierons pas ici, très en détail, les eaux de l'Argens et celles de ses affluents que le rapport C.E.M.A.G.R.E.F., déjà signalé, développe par ailleurs. Nous en dónnons, ci-après, quelques caractéristiques :

- 'les eaux sont relativement fraiches et bien oxygénées sur tout leur parcours. La minéralisation présente certaines particularités en rapport avec la nature du substrat géologique (effleurements triasiques notamment).

- à partir de la source, et jusqu'à Châteauvert, l'Argens présente des eaux moyennement minéralisées dont la conductivité est comprise entre 450 à 550 micromhos $/ \mathrm{cm}$, bicarbonatées calciques, avec des $\mathrm{pH}$ voisins de la neutralité ( $\mathrm{pH}$ compris entre 7,5 et 6,9 ).

- à Châteauvert l'influence du trias, s'ajoutant aux apports de l'affluent * Eau salée *, conduit à une augmentation très importante du taux de chlorures (teneurs variant entre 245 et $526 \mathrm{mg} / \mathrm{l}$ en $\left.\mathrm{Cl}^{-}\right)$ainsi qu'à un degré moindre du taux de sulfates $\left(70-175 \mathrm{mg} / \mathrm{l}\right.$ en SO $\left.\mathrm{SO}_{4}=\right)$. Ces fortes teneurs expliquent les fortes minéralisations : 2025 micromhos $/ \mathrm{cm}$ en juillet 1976 , en période d'étiage, 100 micromhos $/ \mathrm{cm}$ en mars 1977, en saison pluvieuse. Certains résultats ont aussi été influencés par le lavage de sables salés en provenance de l'embouchure. - l'on observe ensuite, vers l'aval et jusqu'au MUY une décroissance régulière du taux de chlorures ainsi que celui des sulfates, avec stabilisation au delà du pont d'Argens (RN 7). On note alors des chiffres qui varient entre 70 et $110 \mathrm{mg} / \mathrm{l}$ pour $\mathrm{SO}_{4}=, 100$ et $150 \mathrm{mg} / \mathrm{l}$ pour $\mathrm{Cl}^{-}$et 700 et $900 \mathrm{micromhos} / \mathrm{cm}$ pour la conductivité.

- il faut noter, en aval du Muy, une nouvelle augmentation du taux des sulfates et, à un degré moindre, des chlorures, par suite de l'apport de la Nartuby (gypses du Keuper) : $130-175 \mathrm{mg} / \mathrm{l}$ en $\mathrm{SO}_{4}=, 130-170 \mathrm{mg} / \mathrm{l}$ en $\mathrm{Cl}^{-}$, pour une conductivité de $900-1000$ micro$\mathrm{mhos} / \mathrm{cm}$.

- dans l'estuaire, à partir de Roquebrune, on note l'influence des intrusions marines (surtout en période d'étiage et par vent du Sud). Sur les figures 8 et 9 , seules les analyses 1 et 3 du tableau II de septembre 1976 ont été reproduites. II est bon de rappeler que sl 
$=$
岁
究

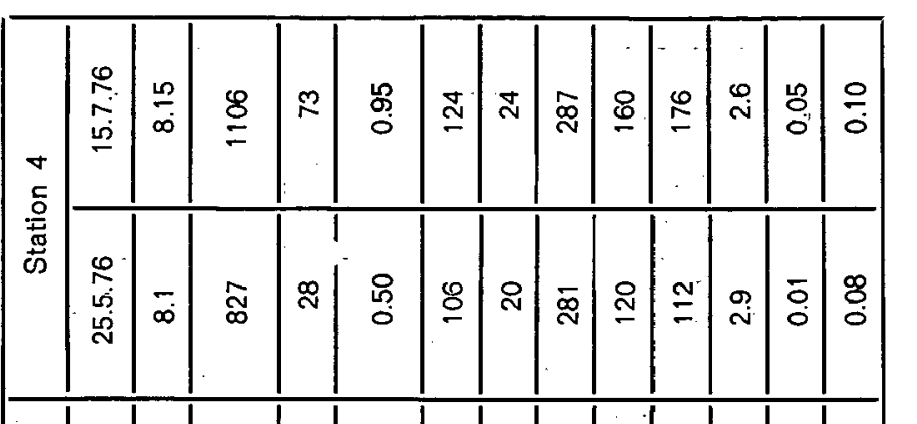

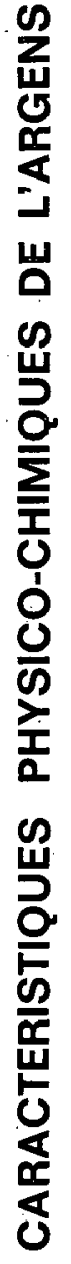

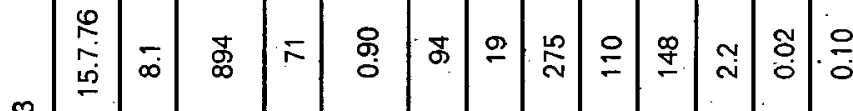

年

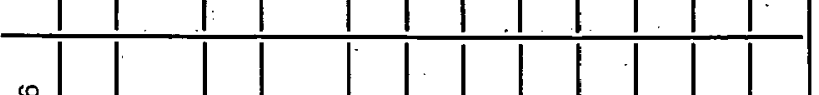

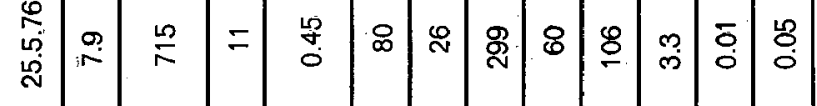

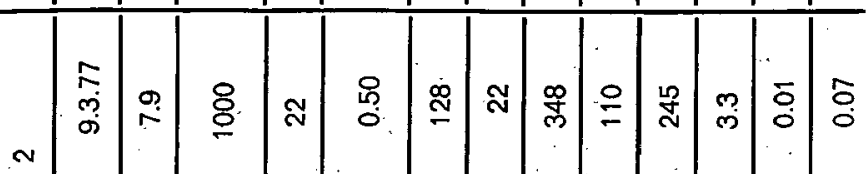

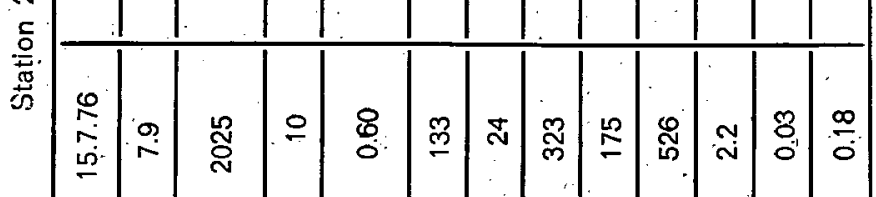

$\sum_{\overline{0}}^{\mathbb{0}} \hat{z}$

赵飔

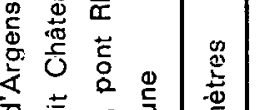

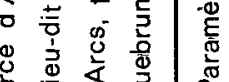

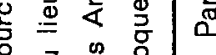

क ब

- $\ddot{1} \ddot{m} \ddot{~}$

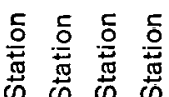

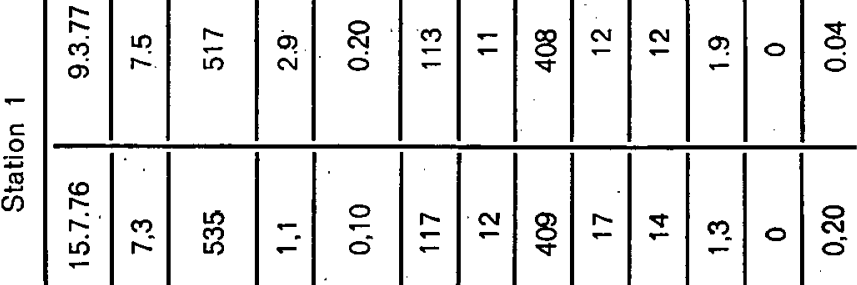

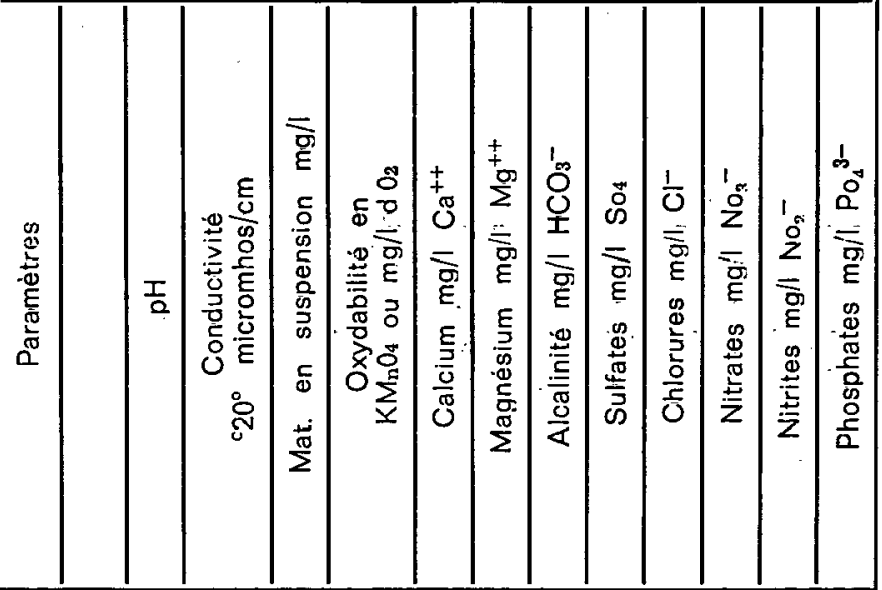




\section{COMPOSITION CHIMIQUE DES EAUX}

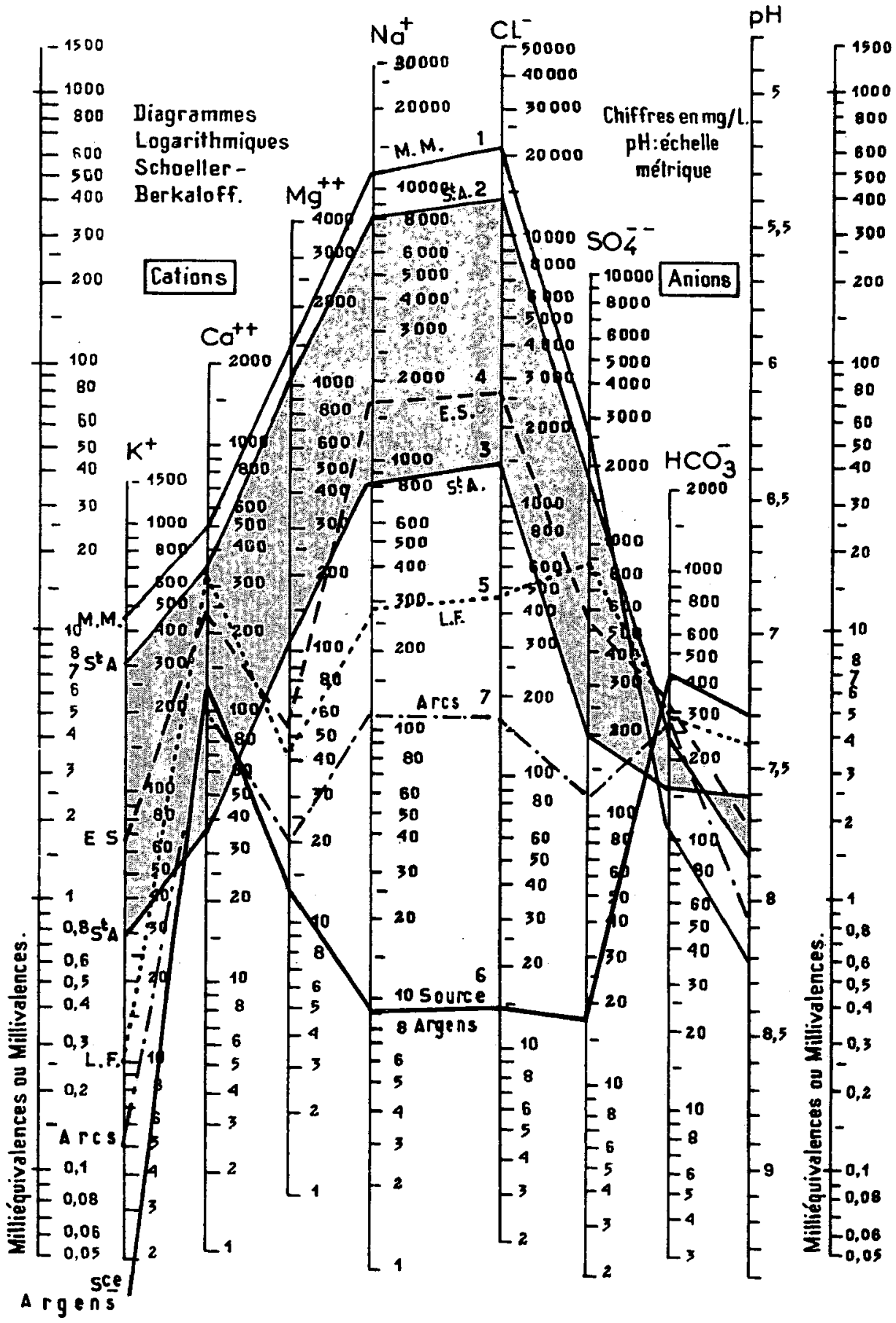


DIAGRAMMES DE MAUCHA

PL. 9.
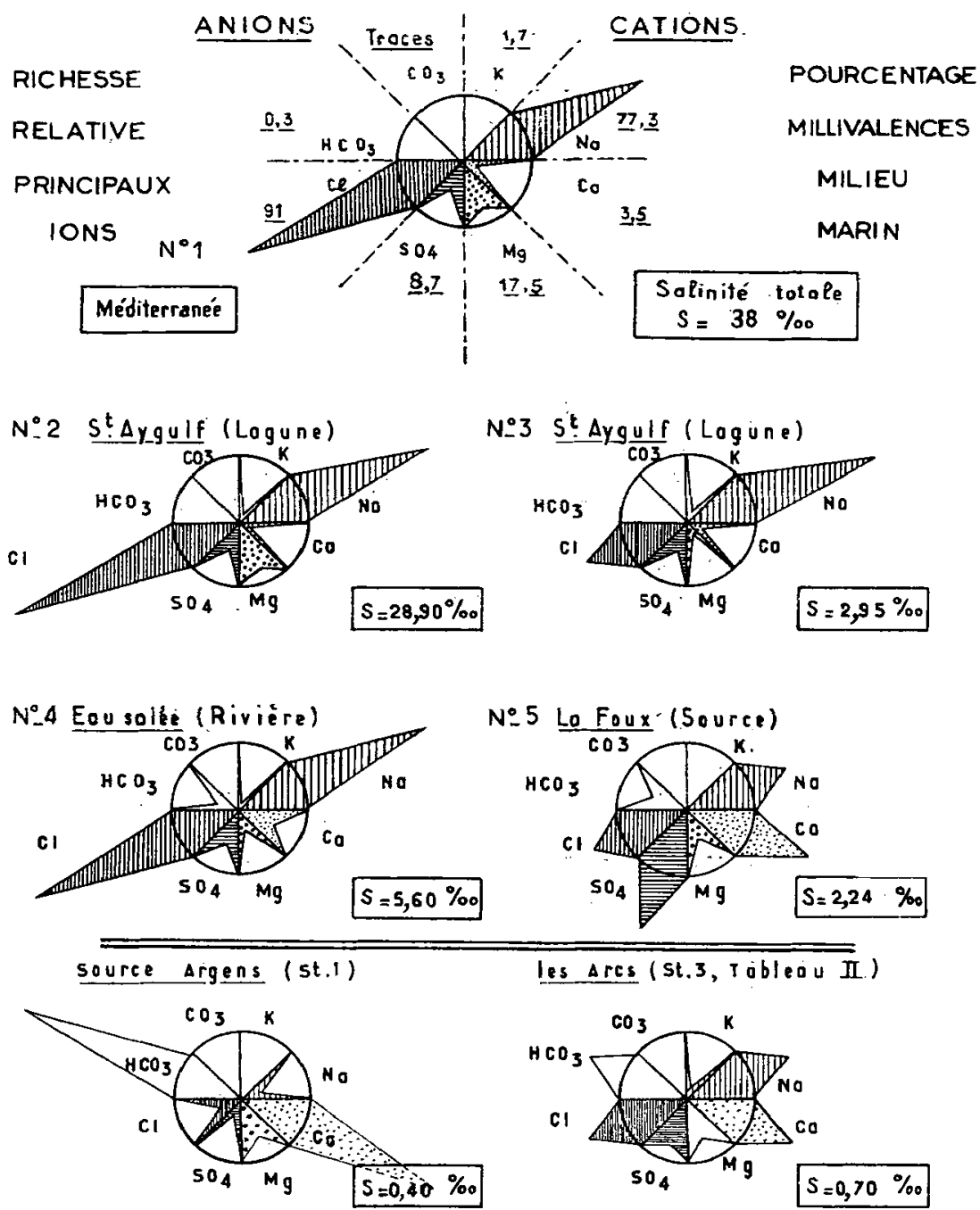

les échelles BERKALOFF (fig. 8) sont des progressions logarithmiques afin de pouvoir plus facilement grouper sur une mème figure, des eaux aux salinités très différentes (pour des questions d'échelles), les graphiques de MAUCHA (1932) font intervenir. ide leur côté, les pourcentages des principaux ions évalués en milli-équivalents. L'on notera, pour les analyses d'eau douce; les fortes proportions de l'ion $\mathrm{HCO}_{3}$ (le graphique source d'Argens au bas de la figure 9 correspond à des eaux douces bicarbonatées-calciques).

L'eau de la source riche en calcium (nous sommes en zone de la Provence calcaire) est bicarbonatée - calcique à près du $90 \%$; celle des Arcs, quoique éloignée de la zone d'apport de * l'Eau salée $*$, en est encore très influencée (importance des ions $\mathrm{Na}^{+}$et $\mathrm{Cl}^{-}$ presqu'aussi importants que les ions $\mathrm{HCO}_{3}^{-}$et $\mathrm{Ca}^{++}$).

Au niveau des pollutions, l'on peut noter quelques secteurs critiques heureusement localisés : le secteur situé en aval de la confluence avec la Meironne (affluent pollué à StMaximin par la ville et la distillerie), le secteur de Châteauvert recevan: ¿l'Eau salée" polluée par la tannerie de Barjols et par des rejets urbains mal épurés, la zone en aval du Muy recevant, par la Nartuby, les rejets des agglomérations de Draguignan et Trans-enProvence. 
$\equiv$
$?$
岕
息
$上$

\begin{tabular}{|c|c|c|c|c|c|c|c|c|c|}
\hline 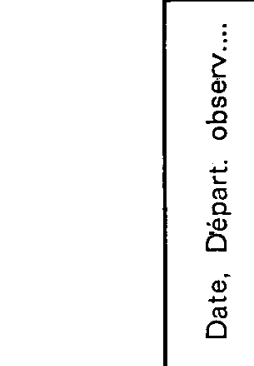 & 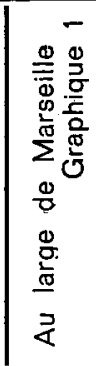 & 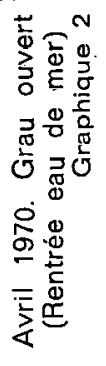 & 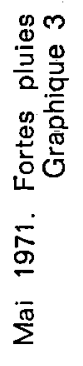 & 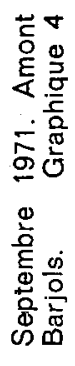 & 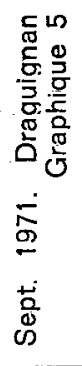 & 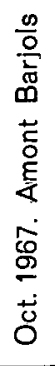 & $\begin{array}{l}= \\
= \\
\frac{\dot{\sigma}}{9} \\
\frac{0}{0} \\
\infty\end{array}$ & 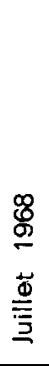 & $\begin{array}{l}\stackrel{\circ}{\circ} \\
\stackrel{\circ}{-} \\
\stackrel{5}{\Xi}\end{array}$ \\
\hline & 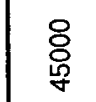 & 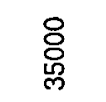 & 总 & 吕 & ঙ্ల్ల & $\frac{8}{6}$ & 号 & 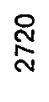 & 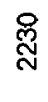 \\
\hline $\begin{array}{l}\frac{8}{0} \\
0\end{array}$ & $\begin{array}{l}\stackrel{8}{\circ} \\
\infty \\
\infty\end{array}$ & 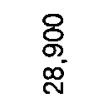 & $\begin{array}{l}\stackrel{8}{\$} \\
\stackrel{N}{N}\end{array}$ & 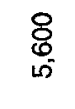 & 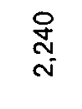 & 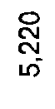 & 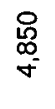 & 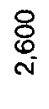 & 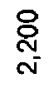 \\
\hline$\frac{T}{\alpha}$ & $\stackrel{\sim}{\infty}$ & $\stackrel{\infty}{\sim}$ & $\stackrel{\mathscr{Q}}{\sim}$ & $\hat{N}$ & $\stackrel{\nabla}{\pi}$ & $\infty$ & $\stackrel{0}{\sim}$ & $\stackrel{n}{n}$ & $\stackrel{20}{\sim}$ \\
\hline $\begin{array}{l}00 \\
0 \\
\text { I }\end{array}$ & 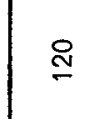 & 品 & $\stackrel{\mathscr{g}}{\longrightarrow}$ & స్ & 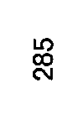 & జ్లొ & 峞 & $\bar{\delta}$ & $\underset{N}{\mathbb{N}}$ \\
\hline ర్ల & 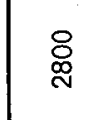 & \&్ & శ్లి & 怘 & 品 & 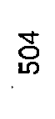 & 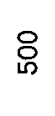 & $\frac{\nabla}{\sigma}$ & 嵩 \\
\hline$\overline{0}$ & $\frac{8}{\circ}$ & 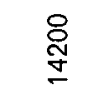 & \begin{tabular}{l}
8 \\
\multirow{2}{*}{}
\end{tabular} & 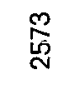 & $\stackrel{\frac{2}{5}}{5}$ & 岕 & 品 & 说 & ஜ্ণ \\
\hline$\stackrel{\pi}{2}$ & ষ্ల్ల & $\frac{8}{\infty}$ & ఖ్లి & $\stackrel{\text { 足 }}{\stackrel{0}{\varrho}}$ & 克 & & 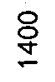 & 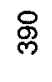 & 요 \\
\hline$\Sigma^{\sigma}$ & 号 & 8 & $\underline{8}$ & 吕 & $\stackrel{\llcorner}{+}$ & $\bar{\infty}$ & पे & जั & $\overline{10}$ \\
\hline$\stackrel{\pi}{0}$ & $\stackrel{P}{*}$ & 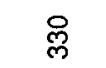 & ले & $\stackrel{\infty}{\mathbb{N}}$ & ి్లి & Nָ & 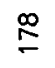 & 总 & 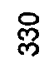 \\
\hline 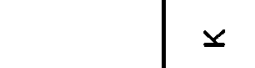 & 昌 & ষ্ల & 이 & $R$ & $\stackrel{ }{\circ}$ & $\stackrel{\mathscr{\infty}}{\infty}$ & $\hat{\imath}$. & \pm & $\infty$ \\
\hline 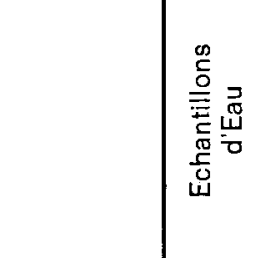 & 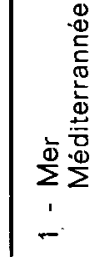 & 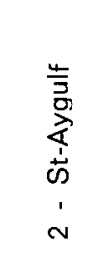 & 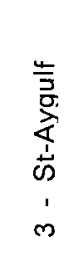 & 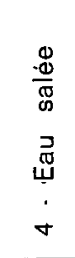 & 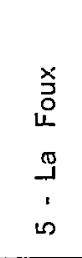 & 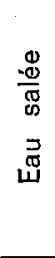 & 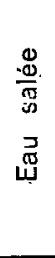 & 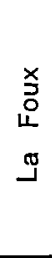 & 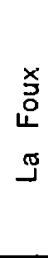 \\
\hline
\end{tabular}


量

\begin{tabular}{|c|c|c|c|c|c|c|c|c|c|c|}
\hline 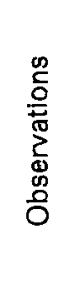 & & $\begin{array}{l}5 \\
5 \\
5 \\
5 \\
5 \\
5 \\
5 \\
5 \\
5 \\
5 \\
5\end{array}$ & & 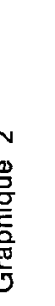 & & & & & & \\
\hline 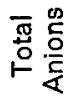 & $\begin{array}{l}\text { J } \\
\text { \& }\end{array}$ & 으 & $\frac{\infty}{\frac{\infty}{f}}$ & $\stackrel{8}{\circ}$ & $\begin{array}{l}\mathscr{0} \\
\dot{0} \\
\dot{\sigma}\end{array}$ & 옹 & $\begin{array}{l}\infty \\
\dot{\sigma}\end{array}$ & 음 & $\begin{array}{l}\text { m } \\
\ddot{8}\end{array}$ & $\stackrel{8}{-}$ \\
\hline $\begin{array}{l}\text { O̊ } \\
\text { O⿱一土 }\end{array}$ & $\sim$ & $\stackrel{m}{0}$ & $\stackrel{\infty}{-}$ & $\bar{\sigma}$ & $\stackrel{\mathscr{N}}{\mathrm{N}}$ & "ే & $\begin{array}{l}\infty \\
1 \\
\nu\end{array}$ & $\bar{\oplus}$ & $\stackrel{\infty}{+}$. & 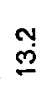 \\
\hline రొలో & 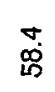 & $\stackrel{\sim}{\infty}$ & P & $\stackrel{\text { ஜ̊ }}{\circ}$ & $\sigma$ & $\stackrel{\sim}{\infty}$ & $=$ & $\stackrel{\leftrightarrow}{=}$ & $\stackrel{\text { L? }}{\lessgtr}$ & ָุ \\
\hline$\overline{0}$ & $\stackrel{8}{8}$ & б & \& & 吕 & $\mathcal{F}$ & $\begin{array}{l}\stackrel{n}{\mathscr{D}} \\
\stackrel{\infty}{0}\end{array}$ & $\stackrel{\infty}{\sim}$ & $\stackrel{\text { జే }}{\text { జ్ }}$ & \pm & $\stackrel{\infty}{\infty}$ \\
\hline 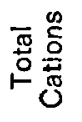 & $\begin{array}{l}10 \\
8 \\
8\end{array}$ & $\stackrel{8}{0}$ & \begin{tabular}{l}
$\infty$ \\
$\infty$ \\
\multirow{y}{*}{}
\end{tabular} & $\stackrel{8}{0}$ & $\begin{array}{l}\mathscr{L} \\
\infty \\
6\end{array}$ & 8 & $\stackrel{m}{\circ}$ & $\stackrel{\circ}{\circ}$ & 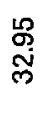 & 8 \\
\hline$\frac{\pi}{2}$ & $\stackrel{\mathscr{3}}{3}$ & $\stackrel{m}{i}$ & 울 & 冓 & "్ల & $\stackrel{L}{\stackrel{L}{N}}$ & $\mathbb{N}$ & $\stackrel{\text { के }}{\Omega}$ & $\underline{m}$ & ه్లి \\
\hline$\frac{\sigma}{2}$ & 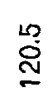 & 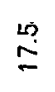 & $\stackrel{\llcorner}{\infty}$ & 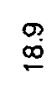 & $\stackrel{+}{\circ}$ & 요 & $\stackrel{L}{+}$ & in & $\hat{m}$ & $\stackrel{\stackrel{N}{=}}{=}$ \\
\hline 8 & $\stackrel{\text { నె }}{3}$ & $\stackrel{\text { Ln }}{m}$ & 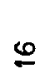 & $\stackrel{\leftrightarrow}{\oplus}$ & $\cong$ & $\hat{m}$ & $\simeq$ & $\stackrel{m}{=}$ & $\mathscr{\theta}$ & $\begin{array}{l}\text { هo } \\
\stackrel{\infty}{\alpha}\end{array}$ \\
\hline$x$ & $\stackrel{?}{=}$ & $\cong$ & N & $\stackrel{\varphi}{\varrho}$ & $\frac{n}{\sigma_{0}^{-1}}$ & $\stackrel{\varphi}{\circ}$ & $\stackrel{\infty}{-}$ & i & $\stackrel{\text { ָே }}{\circ}$ & $\stackrel{\infty}{\circ}$ \\
\hline \multirow{2}{*}{ 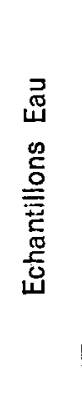 } & $\overline{\bar{\Phi}}$ & $\begin{array}{c}\stackrel{0}{E} \\
0 \\
0\end{array}$ & $\overline{\overline{\mathrm{d}}}$ & $\begin{array}{c}\stackrel{0}{E} \\
\text { ک }\end{array}$ & $\overline{\overline{\mathrm{\omega}}}$ & $\underset{\mathrm{g}}{\stackrel{\mathrm{g}}{\mathrm{\sigma}}}$ & $\bar{\Phi}$ & $\begin{array}{c}\stackrel{0}{\xi} \\
\text { oc }\end{array}$ & $\bar{\Phi}$ & $\begin{array}{c}\stackrel{\boldsymbol{\omega}}{\mathbf{g}} \\
\sigma^{\circ}\end{array}$ \\
\hline & $\begin{array}{l}\frac{a}{2} \\
\dot{a} \\
-\end{array}$ & 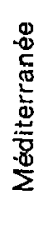 & 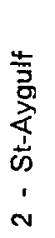 & 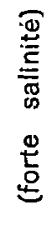 & 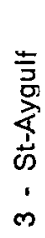 & 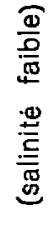 & & & & \\
\hline
\end{tabular}


- Pour le moment l'impact des pollutions n'est pas trop important et semble limité à la période estivale où l'on note la présence de nitrites et de sels ammoniacaux dans ces secteurs.

Les deux sources saumâtres de l' Eau salée * près de Barjols et de * La Foux *, près de Draguignan, ont des salinités respectivement voisines de $5 \mathrm{~g}$ et $2 \mathrm{~g} / \mathrm{l}$, avec de légères variations saisonnières. Elles sont d'ailleurs marquées par quelqués éléments d'une flore et d'une faune saumâtres (KIENER et PETIT, 1968), en particulier Potamopyrgus jenkinsi, Theodoxus fluviatilis (mollusques) et Ruppia roestellata (algue verte).

Quelques unes des analyses chimiques ont été reportées sur les tableaux III et III bis (milliéquivalents correspondant aux chiffres du tableau III) et transcrites sur les graphiques des fig. 8 (BERKALOFF) et 9 (MAUCHA). La salinité de la source *Eau salée * influence fortement le ruisseau de Varrage (qui devient alors "l'Eau salée ") jusqu'au grand pont de Barjols et la minéralisation de l'Argens s'en ressent nettement.

Nous avons déjà signalé que l'eau de la Foux est utilisée pour un éievage de truites, mais l'on sait qu'une légère salinité (ici $2 \mathrm{~g} / \mathrm{l}$ ) est même excellente (catalyseur de croissance et lutte contre les parasites de la peau).

Dans la fig. 8 où les abréviations indiquées correspondent aux stations suivantes :

M.M. - Mer Méditerranée ( $\left.n^{\circ} 1\right)$

St A - Lagune de Saint-Aygulf (2 et 3 )

E.S. - Rivière de l'Eau salée (4)

L.F. - Résurgence de la Foux (5) ;

l'on remarquera d'une part le parrallélisme entre l'eau de la lagune de St-Aygulf et celle de la Méditerranée (ce qui est normal puisque la lagune a une eau de mer diluée) et, d'autre part, l'influence des formations calcaires (importance de l'ion $\mathrm{Ca}$ ) sur les eaux saumâtres de la Foux et l'Eau salée.

La zone en bistre représente les limites de salinité entre lesquelles evoluent les eaux de la lagune de St-Aygulf au cours des saisons. Ce gradient de salinité a une influence directe sur les mouvements des espèces euryhalines entre mer et lagune.

Dans l'estuaire les eaux, par influence marine, sont de plus en plus salées et cette salinité peut d'ailleurs être en relation avec le vent, notamment le vent " marin s (du sud) qui peut faire remonter les eaux saumâtres bien au-delà du pont de D. 8 . Par périodes de crues du cours d'eau, l'estuaire est bien odéssalé * et l'eau de l'Argens peut pénétrer assez loin en mer, ayant alors un effet d'appel certain sur les espèces euryphalines (muges et loup, notamment) venant coloniser sporadiquement la zone estuarienne.

\section{CHAPITRE III}

\section{FAUNE ICHTYOLOGIQUE}

\section{1 - ESPECES D'EAU DOUCE (Tableau IV, Fig. 10 et 11).}

La liste des poissons dulcicoles pour l'ensemble du bassin versant est précisée par ie tableau IV totalisant 26 espèces, dont probablement 8 à 10 autochtones et 18 à 16 introduites. Parmi ces dernières, toutes ne sont pas retrouvées, soit qu'elles n'aient pas trouvé de biotopes favorables, soit éliminées par les fortes crues. De toutes façons, le nombre d'espèces introduites est relativement élevé et une partie ne se maintient dans le cours d'eau que par apports répétés (truites arc-en-ciel, en particulier).

Signalons que les blageons de la Nartuby ont été étudiés par d'AUBENTON, DAGET et SPILLMANN (1970) et que la région du Sud-Est parait particulièrement intéressante pour la mise en évidence du polymorphisme de l'espèce par i'existence de races locales suivant les cours d'eau : Argens, Var et Roya.

Nous nous limiterons, ici, à quelques observations relatives aux principales espèces rencontrées et précisées (par ordre alphabétique des noms scientifiques) au tableau IV. Les lecteurs qui voudraient de plus amples renseignements sur leur biologie générale pourront se reporter, entre autres, à l'ouvrage de SPILLMANN (1961).

Brème. Surtout abondante en zones $n^{\circ}$ II et IV, elle peut dépasser le poids de $2,5 \mathrm{~kg}$. Elle est aussi abondante dans le lac de Carcès où son explosion démographique récente (1979) pourrait poser quelques problèmes pour la bonne gestion piscicole du plan d'eau.

Ablette. II est difficile de savoir si l'espèce est autochtone ou introduite. Elle est souvent localisée (conditions écologiques à préciser) et on la rencontre le plus fréquemment en amont de Carcès. 
$\geq$
$?$
㟧
愛

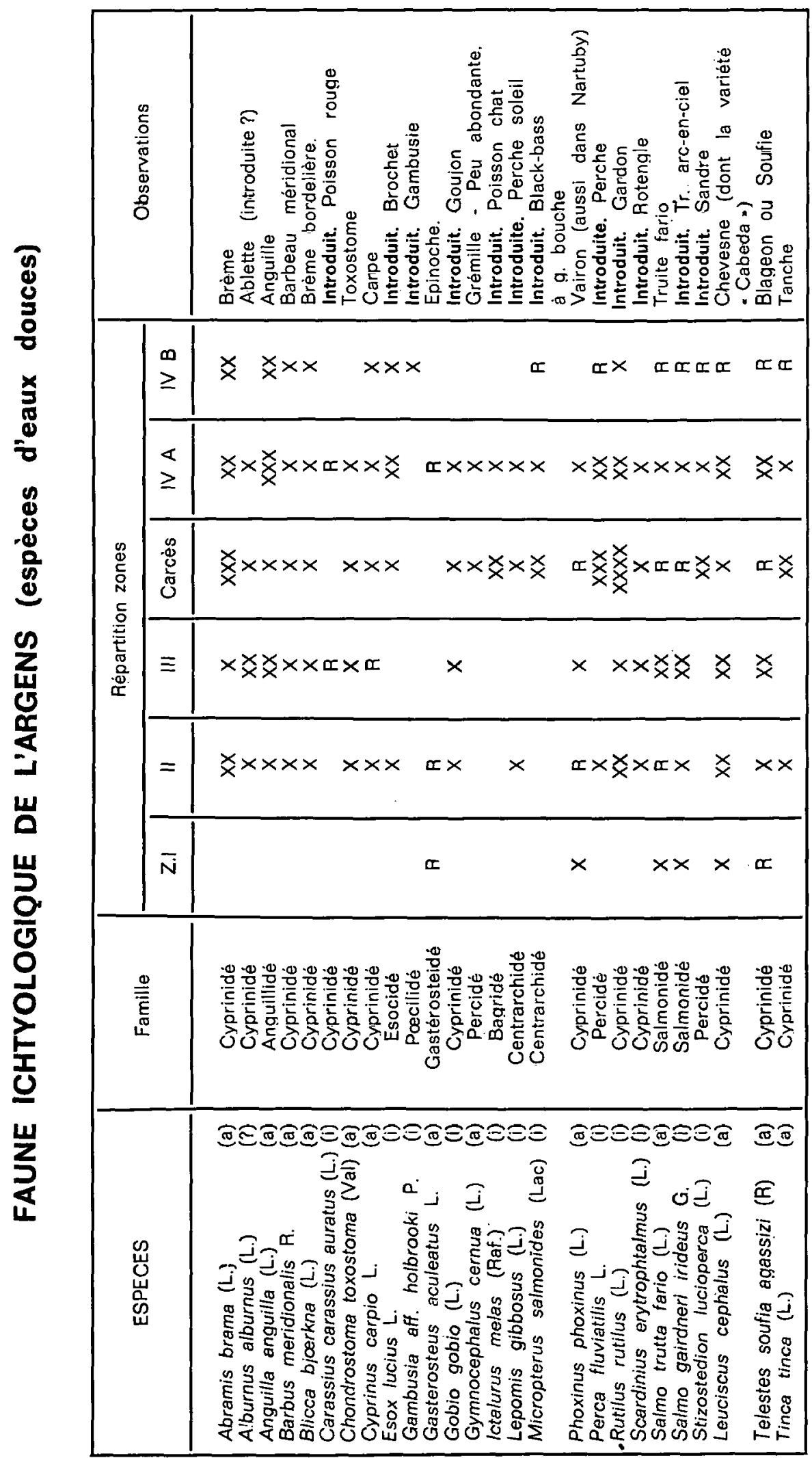




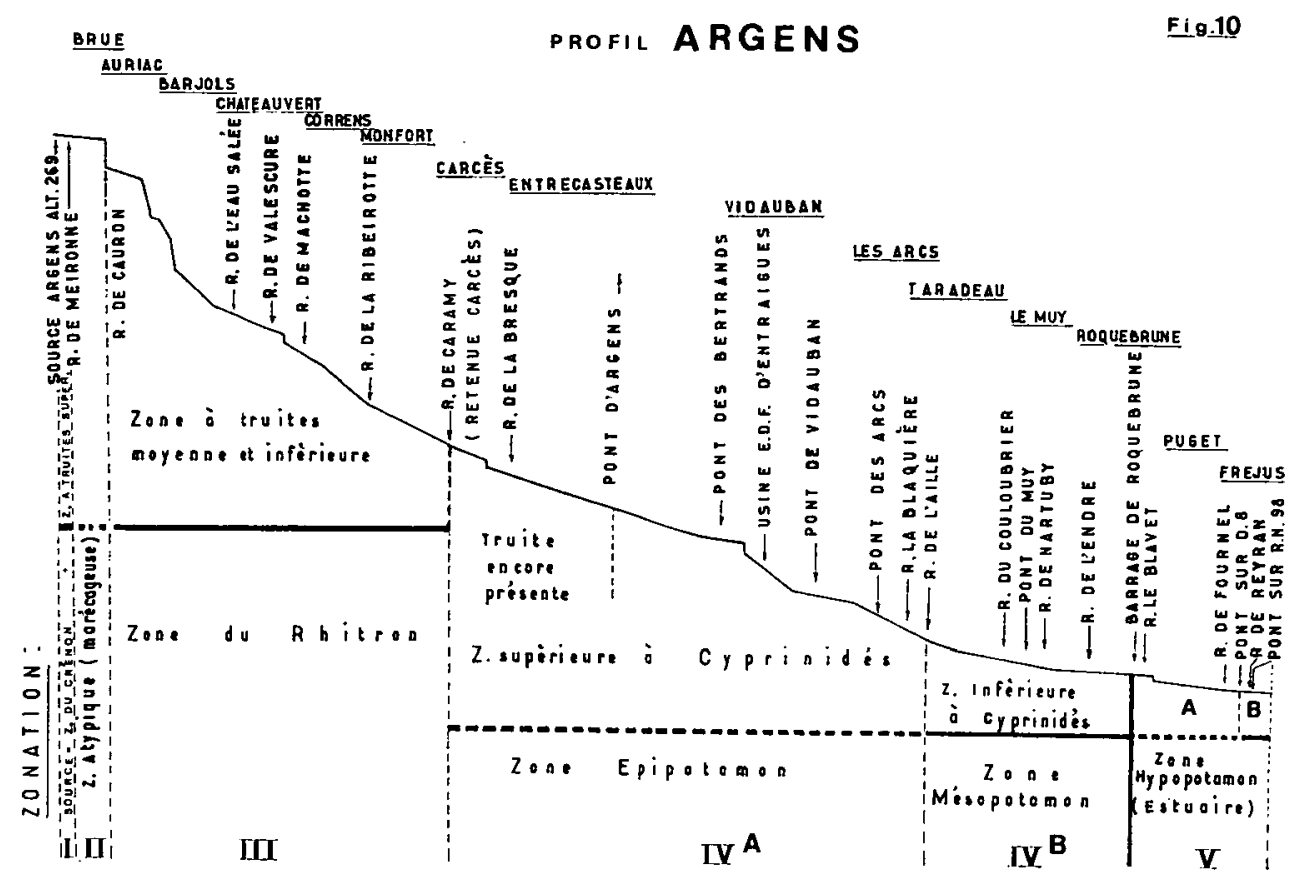

Anguille. Comme dans bien des cours d'eau, l'anguille est présente dans l'Argens et elle est surtout abondante en aval de Carcès. Elle fréquente presque tous les affluents, notamment l'Aille et le Caramy, mais elle ne remonte pas dans l'lssole à partir du lac de Carcès (?) $\mathrm{Si}$ les diverses espèces ne peuvent remonter les rapides de la sortie du lac, il faut signaler que ces derniers ne présentent pas d'obstacle pour la remontée de l'anguille. On la trouve dans plusieurs biotopes : zones de rochers ou de sables, zones sablo-vaseuses, végétation aquatique..

Barbeau méridional. L'espèce existe un peu partout tout au long de l'Argens, mais elle colonise surtout les affluents, entre autres le Caramy et l'Issole. Elle est peu abondante dans le lac de Carcès.

Brème bordelière. Restant de taille très limitée, sa biologie et sa répartition sont très analogues à celle de la brème commune, mais elle est peu abondante.

Toxostome. C'est une espèce qui reste généralement dans des zones bien localisées, notamment dans celles des gravières aux époques de ponte. On la rencontre assez abondamment de la zone mixte $n^{\circ} \|$ jusqu'en aval de Carcès (IV A).

Carpe. Plusieurs races de carpe (courantes en France) existent dans I'Argens : carpe commune, carpe miroir et carpe cuir: Elle peut dépasser $20 \mathrm{~kg}$. Elle se rencontre surtout en zone II et IV et dans la retenue de Carcès, sans jamais être très abondante.

Brochet. II est surtout abondant en aval de Carcès. Ayant peu de possibilités de se reproduire, les meilleurs empoissonnements se font avec des alevins à vésicule résorbée déversés dans les herbiers denses.

Gambusie. Cette petite espèce (introduite pour la lutte contre les moustiques) se localise dans les endroits calmes de la zone inférieure à cyprinidés.

Epinoche. Relativement rare, cette espèce se localise dans la zone d'anciennes gravières recolonisées par la végétation.

Goujon. Existant dans l'Argens et dans pratiquement tous ses affluents, le goujon est souvent bien localisé et il est abondant dans le Caramy, en aval de Brignoles

Grémille. Cette espèce est autochtone dans certaines zones du Sud-Est, mais il est difficile d'affirmer qu'elle l'est ici (?). De taille réduite (max. $15 \mathrm{~cm}$ ), on la rencontre surtout en aval et dans la retenue de Carcès.

Poisson chat. Indésirable dans nos cours d'eau, l'espèce n'est heureusement jamais abondante (taille maximum de $20 \mathrm{~cm}$ ). Dans le lac de Carcès, les jeunes forment des nuages importants an boules, mais une mortalité importante limite beaucoup le nombre des adultes.

Perche soleil. Cette espèce a probablement été introduite par erreur avec des lots de très petits alevins (différenciation difficile). 
$ㅍ$
$\div$
$\overline{1}$

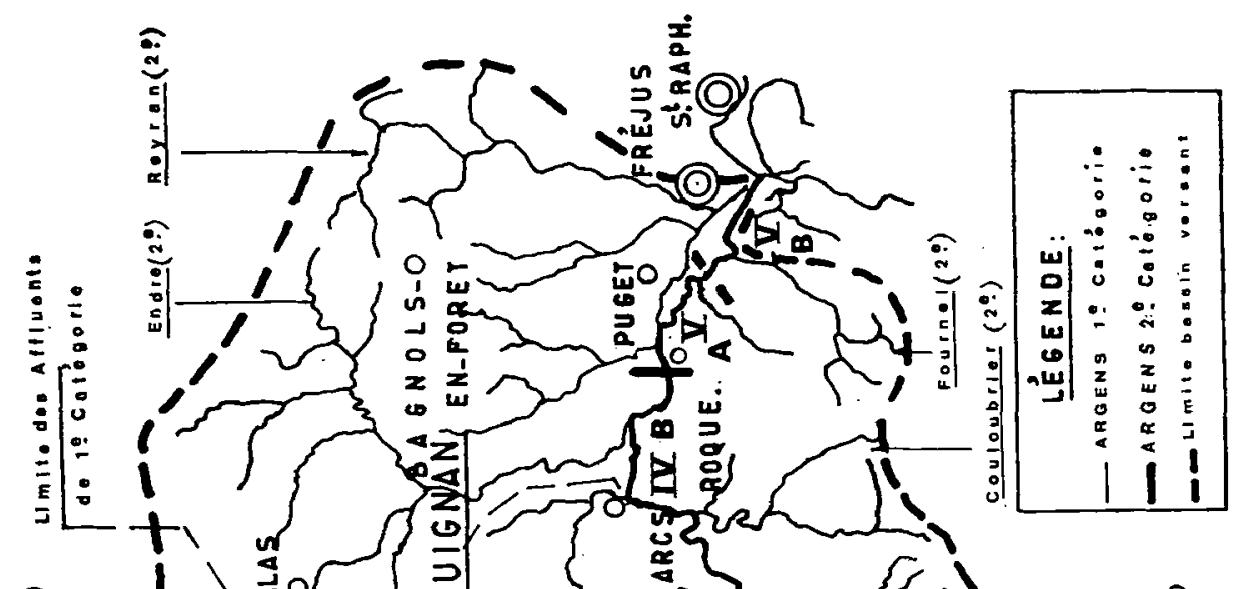

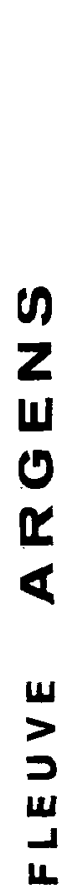
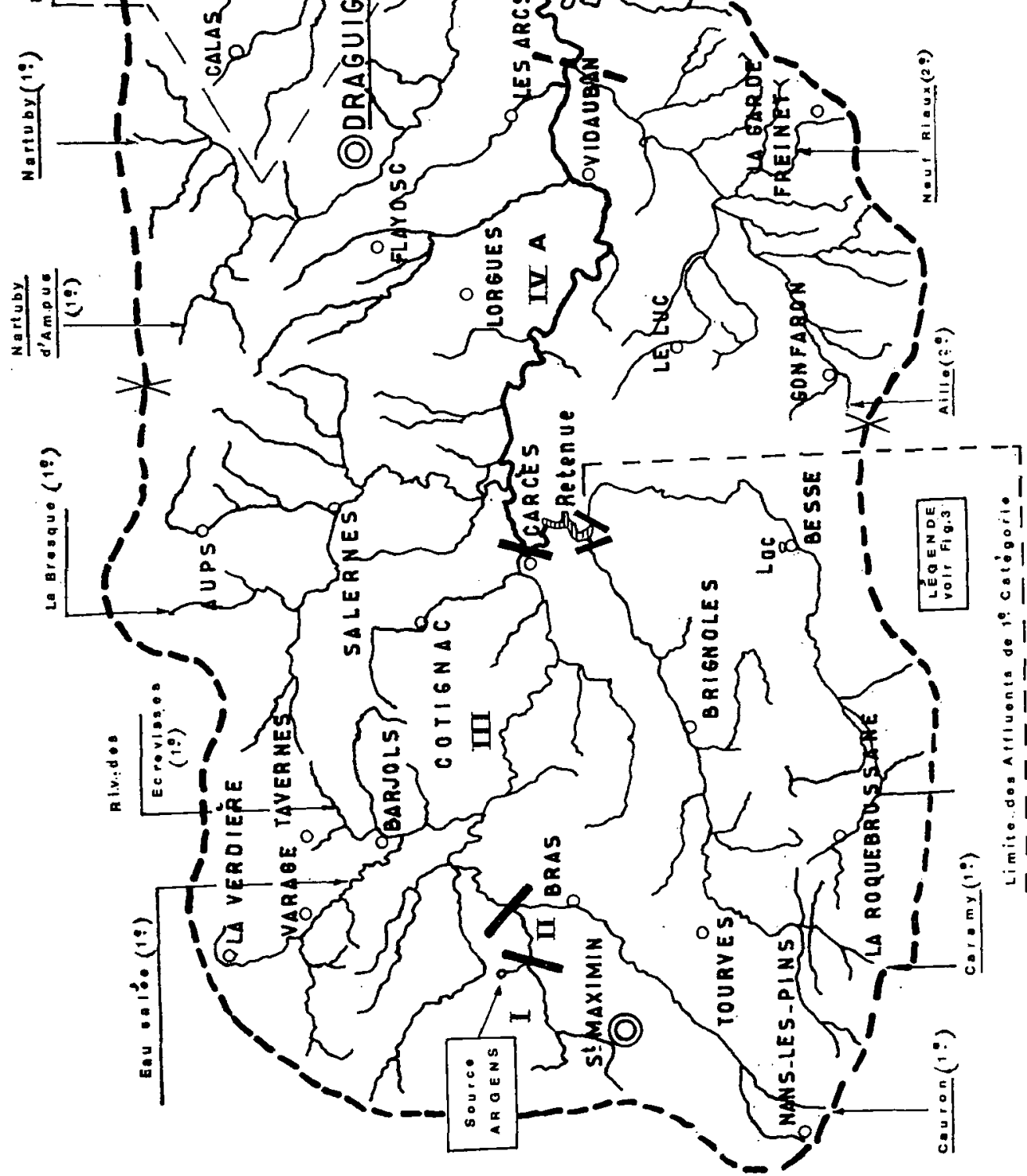
Black-bass. Peu nombreux, les Black-bass (espèce à grande bouche) peuvent atteindre des tailles de 30 à $40 \mathrm{~cm}$. On le rencontre surtout dans la retenue de Carcès et dans les grandes cavités laissées par les carrières de gravier après exploitation.

Vairon. Jamais très abondant, c'est l'accompagnateur typique de la truite.

Perche. Cette espèce atteint de belles tailles dans l'Argens et la retenue de Carcès (jusqu'à $1,5 \mathrm{~kg}$ ) ; les jeunes vivent en colonies, près des bonds.

Gardon. Comme dans le Gapeau, cette espèce atteint ici de belles tailles et des poids de 500 grs. Elle est surtout abondante dans la zone 11 et, en aval de Carcès, dans les trous laissés par les gravières.

Rotengle. Biologie analogue à celle du Gardon.

Truite fario et Truite Arc-en-Ciel (introduite). Les sujets autochtones de T. fario deviennent rares et les déversements des deux espèces se font à presque tous les stades : alevins à vésicule résorbée, alevins de 5 à $6 \mathrm{~cm}$ et truites-portion (“de reprise ») peu avant l'ouverture. Comme idans tous les cours d'eau, l'arc-en-ciel est généralement reprise immédiatement; supportant des températures plus élevées que la fario, elle descend un peu plus bas que cette dernière.

Sandre. Surtout abondant dans le lac de Carcès et en aval de Carcès, dans les anciennes gravières, l'espèce peut dépasser dix kilogrammes.

Chevesne. Dans les zones I et III, c'est l'un Jes accompagnateurs de la truite, aimant les courants rapides. II est abondant et atteint des poids de $2 \mathrm{~kg}$. Le chevesne présente souvent une forte pigmentation sur le pourtour des écailles, d'où une coloration générale plus sombre que celle de l'espèce - type Leuciscus cephalus cephalus. C'est la variétè * cabeda * fréquente dans le midi et qui y cohabite avec l'espèce - type.

Blageon. Limité à des tailles de $16 \mathrm{~cm}$, il est assez abondant tout au long du cours d'eau (espèce d'eau vive).

Tanche. L'espèce est peu abondante et localisée, elle peut atteindre $2 \mathrm{~kg}$.

Il est à signaler que les vieux pêcheurs mentionnent la présence, jadis, de la lamproie fluviatile (Lampetra fluviatilis L.) qui a disparu avec la construction des seuils de la zone de Roquebrune.

De même il a été intéressant de constater, au cours du printemps 1980, la capture de quelques spécimens d'alose feinte (Alosa ficta Duh), espèce qui avait disparu du bas Argens. Il est probable que cette espèce migratrice ne sera plis capturée avec la reconstruction des seuils de Roquebrune.

Si le chabot n'a pas été mentionné dans l'Argens, il est intéressant de préciser sa présence (autochtone) dans l'Endre.

Enfin signalons que la Blennie fluviatile ou Bl. Cagnette (Blennius fluviatilis Asso) aurait été introduite dans le lac de Carcès (?). Son maintien dans ce plan d'eau serait donc à vérifier.

Quittons très momentanément les poissons pour rappeier que l'écrevisse américaine (Orconectes limosus Raf.) a été introduite, avec succès, dans la retenue de Carcès, et, dans l'Argens, en aval de Carcès, où elle s'est bien développée. Si l'on ne trouve plus ou pas actuellement d'écrevisse autochtone \& à pattes blanches " (Austropotamobius pallipes Ler.) dans l'Argens proprement dit, signalóns qu'elle existe dans certains affluents, notamment le Cauron, la rivière des écrevisses, le ruisseau de St-Barthélemy (affluent de la Bresquej, ! $a$ Nartuby.

\section{2. - ESPECES EURYHALINES (adaptées aux variations de salinité. Tableau V. Fig. 10).}

Comme pour les autres estuaires des cours d'eau méditerranéens, en particulier ceux de cette zone du Sud-Est : Gapeau et Var, les poissons euryhalins (à affinités marines dominantes) sont nombreux et le tableau $V$ en donne la liste en précisant approximativement les gradients de pénétration dans l'estuaire. Les espèces rencontrées fréquemment dans ce dernier portent sur treize especces, soit trois muges, l'athérine de Boyer, la saupe, trois gobies, deux espèces de sars, le loup, le flet et le syngnathe abaster. Les gobies et les syngnathes sont essentiellement sédentaires, mais les autres espèces voyagent de façon saisonnière ou sporadique entre mer et eau saumâtre où elles viennent en quête de nourriture. Plusieurs f'entre elles ne sont capturées qu'à de faibles tailles ou dans des eaux encore fortement salées.

Signalöns que pendant les ètés particulièrement secs (tel que celui de 1967 par ex.) et par vent * marin * (du sud), l'estuaire comporte, dans sa presque totalité, des eaux à salinité très voisine de celle de l'eau de mer : l'on peut alors y voir s'aventurer plusieurs espèces telles que : rouget (Mullus barbatulus), anchois (Engraulis encrasicholus L.), hippocampe (Hippocampus guttulatus C.) probablement entrainés par les eaux envahissant l'es. tuaire, dorade (Chrysophrys aurata L.) toujours de petite taille, blennie paon (Blennius pavo 


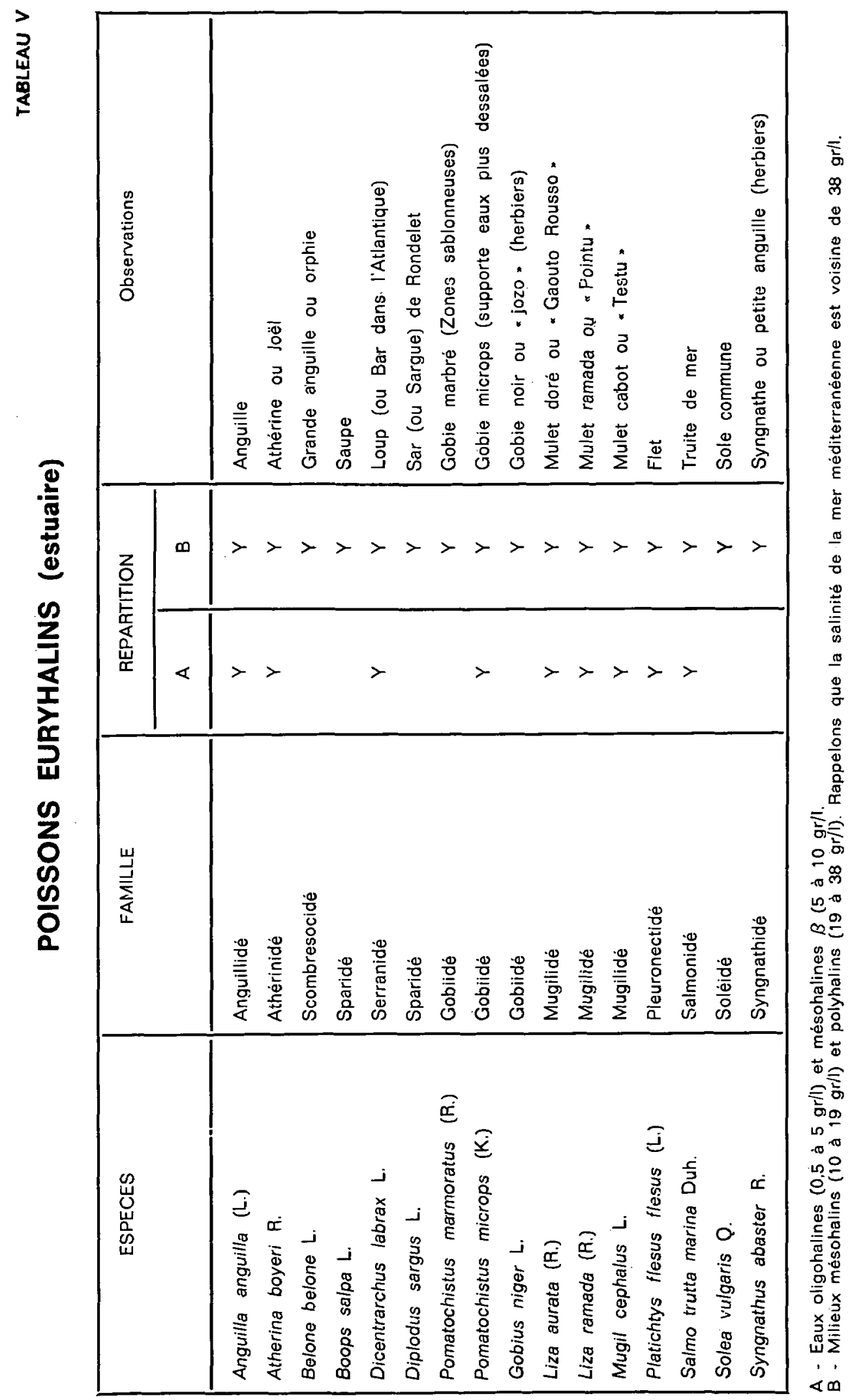


R.), chinchard (Trachurus trachurus L.) et exceptionnellement des jeunes sujets de la petite vive (Trachinus vipera C.V.), de grondins Perlon (Trigla corax B.P.) et de callionyme (Callionymus belenus R.). Il est évident que d'autres espèces à affinitès marines dominantes peuvent y être capturées par circonstances particulières.

Enfin précisons qu'avec l'effondrement des barrages de Roquebrune les muges remontaient jusqu'à Muy (il s'agit essentiellement du Mugil cephalus).

Dans le tableau $\vee$ nous avons indiqué la présence de truites dans l'estuaire. En fait, quelques sujets migrateurs dénommés par les pêcheurs * truites de mer *, y sont capturés certaines années. Les truites étant empoissonnées par boites Vibert, par truitelles ou par sujets mesurant plus de vingt trois centimètres (truites * de reprise * introduites peu avant ou pendant la saison de pêche), une partie se laisse entrainer par le courant pour aller en zone côtière et il serait intéressant d'étudier la corrélation entre la fréquence de ces truites dites a de mer * et l'origine des œufs que la Fédération de pêche importe certaines années de pays nordiques (Danemark en particulier). Ces souches comportent un certain Dourcentage d'individus migrateurs par rapport aux sujets seddentaires (VIBERT, 1967; FABRE, JULLIEN et KIENER, 1974) alors que nos souches autochtones françaises ne portent que sur des sujets d'eau douce.

\section{3 - ZONES PISCICOLES (eaux douces) et ESTUAIRE. CAS DE L'ETANG DE VILLEPEY ET DE LA LAGUNE DE ST-AYGULF. ZONATION: BIOCENOTIQQUE.}

\section{a) Argens. Eaux douces et estuaire.}

Nous avons repris, sur les figures 10 et 11 le profil en long ainsi que le bassin 'versant du cours d'eau. En faisant la synthèse de la répartition et de l'abondance des poissons tout au long de l'Argens et en comparant les zones piscicoles ainsi obtenues à la zonation biocénotique (invertébrés benthiques, notamment Ephèméroptères, Plécoptères, Coléoptères, Elmidés et Trichoptères. Thèse A. DIA, 1978), I'on pourra schématiser, comme suit, la zonation du cours d'eau en se référant aux travaux d'ILLIES et BOTOSANEANU (1963) et BOTOSANEANU (1979). II est cependant utile, au point de vue de la nomenclature utilisée, de rappeler que ces auteurs ont cherché à homogénéiser une certaine typologie à la fois sur le plan des habitats et sur celui des biocénoses en reprenant des travaux antérieurs de STEFFAN (voir BOTOSANEANU, 1979) et nous pouvons alors avoir le schéma approximatif suivant pour un cours d'eau côtier méditerranéen

\begin{tabular}{|c|c|c|}
\hline $\begin{array}{l}\text { HABITAT } \\
\text { (Biotope) }\end{array}$ & $+\underset{\text { Biocénotique }}{\text { ASSOCIATION }}$ & $\begin{array}{l}\text { = ECOSYSTEME } \\
\text { (complexe biotope }+ \text { biocén.) }\end{array}$ \\
\hline Source : Crenal & + Crenon & $=$ Crenocoen \\
\hline $\begin{array}{l}\text { Ruisseau : Rhithral } \\
\text { (z. à truites) }\end{array}$ & + Rhithron & $=$ Rhithrocoen \\
\hline $\begin{array}{l}\text { Rivière : Potamal } \\
(\mathrm{z} \text { à cyprinidés })\end{array}$ & + Potamon & $=$ Potamocoen \\
\hline Estuaire : (eaux saumâtres) & + Hypopotamon & \\
\hline $\begin{array}{l}\text { Mais il ne faut pas oub } \\
\text { t essentiellement une rivière } \\
\text { sse à la suivante ne sont p } \\
\text { ison de la faible variation d' } \\
\text { chevauchement, des zonati } \\
\text { ur les invertébrés benthique } \\
\text { à salmonidés dominants et } \\
\text { alle du Potamon se situe à C } \\
\text { arrivée du Caramy (sortant }\end{array}$ & $\begin{array}{l}\text { que l'Argens, prenan } \\
\text { plaine et que, au fil } \\
\text { ussi marqués que po } \\
\text { Ide d'un habitat au } \\
\text { (chevauchement con } \\
\text { ui, pour les poissons } \\
\text { ne IV à cyprinidés. } \\
\text {, avec une diminutio } \\
\text { retenue de Carcès) }\end{array}$ & $\begin{array}{l}\text { urce à faible altitude }(270 \mathrm{~m}) \\
\text { au, les passages d'une biocé- } \\
\text { cours d'eau de montagne, en } \\
\text { II y a, de ce fait, un certain } \\
\text { galement par DIA, déjà cité } \\
\text { itue le passaae entre la zone } \\
\text { oure entre zone du Rythron et } \\
\text { pente du cours d'eau et avec }\end{array}$ \\
\hline
\end{tabular}

\section{ZONATION PISCICOLE (fig. 10 et 11) :}

- Zone I. C'est la zone de la source (Crenal) dont il est difficile de séparer un tout petit tronçon amont de l'Argens qui constitue la zone supérieure à truites, avec du chevesne, du vairon et un peu de blageon. L'on peut en rapprocher la zone voisine représentée par la Meironne et ses affluents. Typologiquement c'est le secteur supérieur du Rhithron.

- Zone II. Après la confluence avec la Meironne (ou ruisseau de Reyran), la pente de l'Argens devient particulièrement faible et une zone marécageuse s'installe sur le cours d'eau allant pratiquement jusqu'à la chute du Tombereau, juste avant la confluence avec le Cauron. Elle constitue une zone atypique » dans la succession habituelle des zones piscicoles et, à la petite zone à truites, succède une zone mixte avec quelques truites et surtout des cyprinidés dont le peuplement correspond bien $\dot{a}$ ce biotope aux eaux lentes (brême dominante). 
- Zone III. Après la confluence avec le Cauron, la pente du cours d'eau redevient plus forte et -l'Argens comprend une importante zoné à truites, . équivalente . au rhithral, qui va jusqu'à la confluence avec le Caramy (Carcès). C'est une très belle partie de la rivière au point de vue de la pêche, malgré plusieurs pollutions, et sur le plan touristique elle comporte un petit * canyon*, le.vallon Sour, riche en truites. Jusqu'à Carcès le fleuve est classé en $1^{\text {re }}$ catégorie, mais l'on rencontre encore quelques truites fario en aval, jusqu'à Pont d'Argens.

- Zone IV. Plusieurs cyprinidés d'eau vive : chevesne et blageon notamment deviennent' alors abondants et c'est. le début de l'Argens classé en $2^{\mathrm{e}}$. catégorie, zone à rattacher au *Potamon : par la nature de ses biocénoses.

Signalons que la retenue de Carcès (alimentèe par le Caramy et son affluent l'Issole) est également classée en deuxième catégorie, ce qui est normal. Les affluents de l'Argens resteront cependant en $1^{\text {re }}$ catégorie en rive gauche jusqu'au Muy (Nartuby).

Cette zone à cyprinidés d'eau vive (Epipotamal), où viennent encore quelques truites d'amont, ne renferme que peu de cyprinidés d'eau calme qui ne remontent guère: cette zone. IV A va jusqu'au confluent de l'Aille. La zone inférieure IV B, où dominent les cyprinidés d'eau calme accompagnés de leurs prédateurs (brochet, sandre; perche, blackbass), va jusqu'au barrage de Roquebrune et elle est à rattacher au mésopotamon. Effectivement on ne peut la dénommer zone à barbeaux = comme l'on pourrait s'y attendre, car le barbeau méridional est surtout abondant dans les affluents (et le barbeau fluviatile n'existe pas dans l'Argens).

- Zone V. La zone $V$ porte sur l'estuaire, l'influence de la mer pouvant se faire sentir au-delà du pont de la Départementale 8 , notamment par haute mer d'équinoxes et par vent du sud (vent marin). En fait, sur le plan biologique, l'on peut schématiquement diviser cette partie du Bas-Argens, qui est à rattacher à l'hypopotamon, en deux secteurs :

- l'amont, aux eaux douces, oligohalines ou mésohalines (maximum 10\%o) avec quelqués cyprinidés, des muges, le loup, l'athérine de Boyer, l'anguille, la a truite de mer *, le flet, le petit gobie (microps). C'est la zone $V A$, douce en amont, où pénètrent des espèces à large euryhalinité* ;

- la zone aval comprise entre la route départementale 8 et l'embouchure aux eaux souvent mésohalines $\beta$ et polyhalines (10\%o suivant les saisons et les vents) avec des espèces euryhalines, les cyprinidés ne descendant plus dans cetté partie $V$ - $B$ de l'estuaire

Dans ces zones saumâtres, l'on est souvent frappé par l'abondance des aligues marines - euryhalines parmi lesquelles if faut citer :

- Cladophora (probablement glomerata) sur les supports durs tels que galets, rochers, troncs d'arbres morts..

- Enteromorpha prolifera, facilement reconnaissable par ses grosses touffes denses de filaments très fins.

Terminons cet aspect piscicole par un aperçu des poissons du complexe Villepey-StAygulf, ancien exutoire de l'Argens.

En amont, les espèces sont évidemment dulcicoles, avec une dominance de cyprinidés.

- Dans la lagune proprement dite, aux eaux saumâtres colonisées par un herbier important d'algues à affinités marines (Cladophora, Enteromorpha) les espèces euryhalines les plus courantes sont :

- soit des poisssons migrateurs tels que muges, loup, athérine de Boyer et plus rarement des sparidés, le flet, la sole, la saupe.

- soit des poissons sédentaires liés à la présence des herbiers, tels que syngnathes (S. abaster) et petits gobiidés (notamment G. microps).

Le.caractère saumâtre de cette lagune, reliée sporadiquement à la mer par le grau de St-Aygulf (pont de la RN. 98, sis au bord de mer) est affirmé par la présence (et certaines années par l'abondance particulière) d'une petite ariémone typiquement d'eaux saumâtres, Diadumene luciae, liée à la présence de l'herbier (sa biologie a été étudiée par A. KIENER, en 1971).

Toute cette zone fait l'objet, depuis plusieurs années, d'exploitations par des carrières de sable et d'aménagements divers, un tourisme abondant ne contribuant guère, de surcroit, au maintien de la végétation environnante ainsi qu'à la propreté et à la beauté du site!

\section{4 - PECHE.}

Depuis 1976, il n'y a plus de fermeture habituelle de la pêche en $2^{\text {s }}$ catégorie, suite à un arrêté préfectoral du Var. Une période spécifique de fermeture, pendant la reproduc-

\footnotetext{
Espèces euryhalines - Euryhalinité : qui peut supporter de larges variations de salinité. Pour tous pro-
blèmes relatifs aux estuaires et aux eaux saumátres, on pourra consulter I'ouvrage A. KIENER de 1979: Ecologie, physiologie et économie des eaux saumâtres Edit. Masson. Paris.
} 
tion du brochet (Février-Mars) est étendue à l'interdiction de capture de tous les carnassiers : Brochet, Sandre, Perche, Black-bass et bien entendu Salmonidẻs.

Pendant cette période, l'emploi d'une seule ligne flottante ordinaire (telle que définie par f'article 410 du code rural) reste cependant autorisée pour les cyprinidés. Signalons, à titre 'd'information, qu'une réforme de la réglementation de la pêche en $2^{e}$ catégorie est à l'étude au Conseil Supérieur de la Pêche.

Le nombre des cartes vendues ces dernières années.. (sans oublier les touristes) s'élève à environ vingt mille.

L'on sait que le domaine fluvial et le domaine maritime ont pour limite le a point de salure * des eaux, c'est-à-dire le point à partir duquel les eaux deviennent salées. Ce point, légèrement variable au cours de l'année et suivant les facteurs écologiques (crues, ètiages, vents...), n'a pas encore été déterminé par un texte.

En attendant, un accord tacite entre Société de Pêche. Administration préfectorale en Inscription maritime a fixé la limite du domaine maritime au pont de la R.N. 98, mais les espèces euryhalines (mulets et loups, notamment) remontaient jusqu'au premier barrage de Roquebrune et après destruction des deux barrages voisins de cette localité (emportés par les crues de 1978), ces espèces (surtout le muqe céphale) peuvent être rencontrées sporadíquement jusqu'au Muy. En vue de la fixation du point de salure des eaux, le S.R.A.E. (Service Régional d'Aménagement des Eaux) d'Aix-en-Provence exécutait autrefois des prélèvements d'eau tous les trimestres et les eaux étaient en moyenne a douces \& trois fois sur quatre.

Il y a actuellement une sorte de zone mixte, allant de l'embouchure au pont cité, dans laquelle pêchent les inscrits maritimes (deux pour cette zone; ils payent la carte) et les pêcheurs inscrits à la Fédération. Notons que toutes les rives de l'Argens se trouvent sur des terrains privés (pas de domaine public ici) et que la pêche n'est pas autorisée en rive gauche (sur une longueur très limitèe, il est vrai) longeant' le terrain de la base aéronavale.

Pêche professionnelle (aux engins).

Les pêcheurs professionnels de l'estuaire utilisent :

- des filets, parmi lesquels le tramail fixe (avec mailles minimum de $27 \mathrm{~mm}$ ) est le plus courant,

- des verveux simples ou avec ailes, des trabaques (système de trois verveux),

- des nasses avec des mailles de $10 \mathrm{~mm}$ et une entrée de $40 \mathrm{~mm}$.

Signalons aussi qu'en eaux douces ( $2^{e}$ catégorie) les" pêcheurs peuvent utiliser ce même type de nasse et poser 10 cordeaux de 10 hameçons chacun pour les anguilles.

Enfin signalons qu'autrefois se pratiquait, dans la zone mixte, la pêche "au fesquier * qui était une capture à la foëne, éclairée au lamparo.

Les principales espèces pêchées en eau douce sont les suivantes :

Brème. Quelques pêcheurs seulement l'estiment pour la soupe et pour les filets de gros sujets dépassant le kilogramme.

Ablette. C'est l'espèce très estimée pour la friture. Elle s'hybride avec plusieurs autres poissons et il serait intéressant d'ètudier de plus près les variétés obteriues avec le chevesne, le gardon, la brème, le rotengle...

Anguille. Atteignant de belles tailles (plus d'un mètre), elle est présente dans tout le cours d'eau jusqu'en amont de Châteauvert. Elle descend à la mer (avalaison) en octobre-décembre, surtout avec les premières crues, et certaines descentes s'opèrent en \& boules*, les poissons étant agglutinés en une dizaine ou plus d'individus. La remontée des civelles a lieu en février-mars. Elle est surtout pêchée en eau trouble avec des lignes plombées. Considérée comme nuisible en zone de première catégorie, elle fait l'objet de pêches électriques de destruction organisées par la Fédération.

Barbeau méridional (ou barbeau truite). Très estimé, mais peu abondant dans l'Argens. II est assez fréquent dans presque tous les affluents (max. $500 \mathrm{gr}$.).

Carpe. Assez largement répartie et atteignant de grandes talllés (poids supérieur à $20 \mathrm{~kg}$ ), elle n'est cependant pas très pêchée (elle est alors appâtée d'avance).

Brochet. C'est une espèce très estimée. Largement introduit (sous forme d'alevins), il est surtout assez abondant en zones II et IV et dans. la retenue de, Carcès. A certaines périodes, le cours d'eau a été empoissonné avec de gros sujets, mais sans grands résultats pour la production d'alevins.

Poisson-chat. Introduit par erreur, il reste de petite taille et n'est estimé que par quelques amateurs. Après un * démarrage explosif », les populations ont fortement régressé.

Black-bass. Très estimé et assez abondant (surtout dańs la retènue de Carcès), il est cependant difficile à captürer (peut dépasser $2 \mathrm{~kg} \mathrm{500)}$ 
Vairon. Poisson très estimé pour la pêche au vif de la truite et autres carnassiers.

Perchè. Très estimée et très pêchèe, la perche est en concurrence avec d'autrés carnassiers. Elle atteint près de $2 \mathrm{~kg}$ dans la retenue de Carcès à partir de laquelle elle opère de petites migrations dans le Caramy.

Gardon et Rotengle. Ce sont deux espèces parfaites pour la pêche familiale. Introduites massivement, elles atteignent exceptionnellement des poids voisins de un $\mathrm{kg}$ (ce qui est beau pour ces deux poissons) et elles servent de poisson-fourrage aux carnassiers.

Truite fario. Introduite massivement (en plus des sujets autochtones devenus rares), elle peut atteindre 4 à $5 \mathrm{~kg}$ (ces gros sujets n'étant génèralement pris qu'à la pêche électrique).

Truite arc-en-ciel. Introduite massivement en surdensitaire (et de taille minimum réglementaire) peu avant et pendant l'ouverture, elle est reprise immédiatement. car très vorace et peu méfiante.

Sandre. C'est une espèce particulièrement estimée, peu combative, surtout abondante dans la retenue de Carcès et en zone IVA. Elle atteint de grandes tailles dans la retenue avec des poids pouvant dépasser $10 \mathrm{~kg}$.

Chevesne ou \& Cabeda $\$$. Très abondant dans pratiquement tout l'Argens sauf la source et la zone IV B. Seuls les sujets de grande taille sont estimes par quelques amateurs.

Blageon ou Soufie. Peu consommée, cette espèce est surtout utilisée pour la pêche au vif.

Tanche. Très estimée (chair bien meilleure que celle de la carpe), la tanche est surtout présente en zone $1 \mathrm{l}$ et dans la retenue de Carcès. Elle peut dépasser $2 \mathrm{~kg}$.

Enfin terminons cet aperçu de la pêche en disant un mot des captures de l'écrevisse américaine qui, très prolifique, a vù ses pêches se développer ces dernières années. Préférant les eaux chaudes, elle se cantonne essentiellement dans la zone IV.

Nous étant essentiellement limités, dans cette étude, au cours d'eau proprement dit de l'Argens, le lecteur-pêcheur sera cependant intéressé par quelques mots sur la pêche dans les principaux affluents et quelques autres petits plans d'eau du bassin versant.

\section{RIVE DROITE :}

Cauron ( $1^{\text {ro }}$ catégorie). Torrentiel près de sa source, cet affluent peut être sporadiquement à sec en aval. Les principales espèces pêchèes sont la truite, le chevesne et le blageon.

Caramy $\left(1^{r \theta}\right)$. Fortement pollué autrefois par Brignoles, il y a eu une nette amélioration avec la nouvelle station d'épuration. Les principales espèces sont la truite, le gardon, le blageon, le barbeau méridional, le vairon, le goujon.

Issole $\left(1^{r e}\right)$. Cet affluent est quelquefois soumis à des assecs en aval. II renferme de la truite, du barbeau méridional, du blageon, du vairon.

Lac de Besse. Petit plan d'eau communal, il renferme essentiellement des cyprinidés, du sandre. du brochet, de la perche et de l'écrevisse américaine.

Retenue de Carcès ( $2^{\circ}$ catégorie). Créé vers 1933 en vue d'alimenter Toulon en eau potable, ce plan d'eau renferme, en plus des espèces autochtones idu Caramy et de l'Issole, de nombreuses espèces introduites dont certaines populations (brochet par ex.) sont maintenues par constants réempoissonnements.

Le Sandre et la Perche s'y sont particulièrement bien acclimatés. Ce plan d'eau attire de très nombreux pêcheurs. Certaines années les travaux nécessitent un fort abaissement du plan d'eau et il est alors massivement réempoissonné. .

Aille $\left(2^{\circ}\right)$. Cet affluent présente quelquefois, en aval, des assecs accusés. La pollution y est faible et il y a eu amélioration par disparition des sablières et des installations de lavage de graviers. Il renferme un peu de truites, de nombreux cyprinidés (dont le barbeau méridional) et vers le confluent, du sandre. La rivière est particulièrement riche en anguilles.

\section{RIVE GAUCHE :}

Eau salée $\left(1^{r \theta}\right)$. Donnant suite au ruisseau de Varrage, la rivière était très polluée par les tanneries de Barjols, mais récemment des progrès ont pu être constatés par diminution de ces industries. Les principales espèces sont la truite, le barbeau et le blageon. Il est à signaler l'écrevisse à pieds blancs dans le ruisseau des écrevisses qui est un de ses affluents.

La Bresque $\left(1^{\text {io }}\right)$. Très jolie rivière à truites qui ne s'assèche pas. Les autres espèces sont le barbeau méridional, le chevesne, le blageon, le vairon et le goujon (ainsi que des tanches et des gardons venant d'une propriété voisine). Les aiguilles sont rares : elles montent, semble-t-il, de préférence dans l'Argens, vers Barjols, attirées par l'odeur des 
tanneries. Il faut signaler la présence d'écrevisses à pattes blanches dans le ruisseau de la Braque, à St-Bartélémy (Aups).

Nartuby $\left(1^{r e}\right)$. Cet affluent renferme des truites et de nombreuses espèces de cyprinidés échappés des piscicultures en aval de Draguignan. Les espèces autochtones portent sur le barbeau, le blageon, le goujon, le vairon, les anguilles. Le ruisseau contient également des écrevisses à pattes blanches et, en aval, des écrevisses américaines (La Foux).

Endre $\left(2^{\circ}\right)$. La truite y est rare; le ruisseau était classé autrefois en $1^{\text {re }}$ catégorie. Les espèces qui y dominent sont : les Cyprinidés introduits, le blageon, le vairon, le barbeau méridional, l'anguille (nombreuses). L'on peut y observer, comme dans le bas-Argens d'ailleurs, des caridines : petites crevettes d'eau douce à rattacher à l'espèce Atyæphyra desmaresti Mill.

Reyran $\left(2^{\mathrm{e}}\right)$. Souvent à sec, cet affluent est fréquemment pollué par des gravières à l'aval. Il ne renferme que peu de poissons : vairon, goujon, blageon, anguille. Dans le bas on peut assister à quelques remontées d'espèces euryhalines.

La partie aval est déviée et canalisée, depuis l'autoroute jusqu'en amont de l'embouchure de l'Argens, Le régime pour la pêche reste fluvial jusqu'à l'Argens et l'on y capture, entre autres, du loup et surtout des muges

\section{CHAPITRE IV}

\section{PROBLEME DES GRAVIERES-SABLIERES.}

L'Argens faisait autrefois l'objet de plusieurs exploitations de sable et de graviers, mais il faut bien dire que pour l'ensemble du bassin versant la situation s'est bien améliorée ces dernières années : sur l'Aille l'exploitation (Entreprise Chioccia) s'est arrêtée et la seule exploitation qui reste pour les affluents est celle de Perrin près de Lorgues, au confluent des Miquelets. Plusieurs entreprises travaillent encore sur les bords de l'Argens proprement dit, mais en dehors du lit actuel et fort heureusement en circuit fermé :

- près de Roquebrune, gravière très importante des Etablissements Perrin, un peu en amont du pont médiéval.

- gravière près du Muy,

- gravière située à Pont d'Argens,

- l'usine SPAT - FLUOR a réglé récemment ses problèmes par des bassins de décantation.

Un problème particulier se pose à l'embouchure avec les exploitations de sable dont l'importance pourrait amener une modification pour la détermination de la limite du point de salure des eaux. Autrefois il se formait un cordon a antisel s à l'embouchure, cordon qui restait légèrement ouvert en période de basses eaux (été notamment) et qui était emporté en mer lors des fortes crues. Avec l'exploitation très intense du sable, la mer remonte ces dernières années bien au-delà de l'embouchure, créant un véritable estuaire où pénètrent les espèces euryhalines, les espèces d'eau douce étant refoulées vers l'amont. Par ajlleurs l'exploitation intensive des sables empêche, dans une certaine mesure, le maintien des belles plages, telles que celles de St-Aygulf et celles voisines de l'embouchure actuelle de l'Argens. C'est un problème qui mériterait attention en vue de préserver la qualité de ces plages dans l'avenir (problème à étudier).

\section{CONCLUSION}

Parmi les cours d'eau côtiers méditerranéens l'Argens présente un intérêt certain pour la pêche. L'on aura noté l'importance, au sein des populations ichtyologiques, des espèces introduites.

Actuellement, le cours d'eau ne pose pas de très gros problèmes pour la vie piscicole, mais il est évident que plusieurs améliorations sont souhaitables dans les domaines de la pollution et de l'exploitation des dernières gravières. Un nettoyage du lit (arbres tombés, berges effondrées dans le domaine privé...) améliorerait, en bien des endroits, la qualité du milieu. Des efforts de moyenne importance permettraient de retrouver un cours d'eau bien rajeuni et susceptible d'entretenir une population de poissons plus importante, ce qui, sur le plan technique, pourrait limiter les empoissonnements qui comptent actuellement de façon importante dans le budget de la Fédération du Var.

\section{BIBLIOGRAPHIE}

ARRIGNON J., 1970. Aménagement piscicole des eaux intérieures. Paris, Edit. Sedetec : $600 \mathrm{pp}$. 
AUBENTON F. d', DAGET J. et SPILLMANN C.J., 1971. Classification numérique des blageons, Leuciscus (Telestes) soufia (Cyprinidæ). Bull. Mus. Nat. Hist. Nat., Paris, $2^{\circ}$ série, 42 (5) : 839 - 848.

BOTOSANEANU L., 1979. Quinze années de recherche sur la zonation des cours d'eau : 1963 - 1978. Amsterdam Bijdragen tot de Dierkunde, 49 (1) : 109 - 134.

BOUGIS P., 1959. Poissons marins. Paris, Edit. Boubée (Atlas des poissons). 1 et 2 : 201 et $234 \mathrm{pp}$.

CORROY G. et DENIZOT G., 1935. Guide géologique de la Frovence occidentale. Ann. Fac. Sci. Marseille, 8 (1) : $172 \mathrm{pp}$.

DECAMPS H., 1971. La vie dans les cours d'eau. Coll. *Que sais-je? * n० $1452: 128$ pp.

DIA A., 1978. Etude écologique et essai de zonation d'une rivière côtière méditerranéenne: i'Argens (Var).

Thèse Fac. Sciences Aix-Marseille III (Lab. Hydrobiologie), 155 pp.

DORIER A., 1957. Répartition du barbeau méridional (Barbus meridionalis RISSO) dans le sud-est de la France. Trav. Lab. Hydrob. et Pisc. Grenoble (Années 1956-1957), 141149.

FABRE F.; JULLIEN R. et KIENER A., 1974. Capture d'une truite de mer aux Goudes, près de Marseille (BDR). Bull. Muséum Hist. Nat. Marseille, $34: 297$ - 303.

FEDERATION PECHE VAR, 1971. (Fédération Départementale des Associations de Pêche et de Pisciculture du Département du Var). La pêche en eau douce dans le Var. Brochure $27 \mathrm{pp}$.

GOUVERNET Cl., Trias de Provence occidentale. Dans * Le Trias de la France et de régions limitrophes ». Mém. B.R.G.M., $15: 165=176$.

GUEIRARD S., 1959. Description pétrographique et zonéographique des schistes cristallins des Maures. Thèse Marseille 1957 (Public. Trav. Lab. Géologie. Marseille. 6).

HARANT $H$. et JARRY D., 1961. Guide du naturaliste dans le Midi de la France. Vol. I : Le littoral. Les étangs. Edit. Delachaux et Niestlé : $261 \mathrm{pp}$.

HUET M., 1949. Appréciation de la valeur piscicole des eaux douces. Trav. Stat. Rech. Groenendaal, série D, $10: 55 \mathrm{pp}$

HUET M., 1954. Biologie, profils en long et en travers des eaux courantes. Bull. Franç. Pisc., $175: 41-53$.

HUET M., 1962. Influence du courant sur la distribution des poissons dans les eaux courantes. Rev. Suisse Hydrobiol., 24 (2) : 412 - 432.

ILLIES J. et BOTOSANEANU L., 1963. Problèmes et méthodes de classification de la zonation écologique des eaux courantes, considérées surtout du point de vue faunistique Stuttgart. Assoc. Intern. Limn. théor. et appl., Communication $12: 57 \mathrm{pp}$.

KIENER A., 1971. Contribution à l'écologie, la physiologie et l'éthologie de l'actinie Diadumene luciæ Verrill. Bull. Soc. Zoolog. France, 96 (4) : 581 - 603.

KIENER A. et OLLIER J., 1970. Contribution à l'étude écologique et biologique de la rivière le Gapeau (Var). Hydrobiologia, 36 (2) : 189 - 251.

KIENER A. et PETIT G., 1968. Contribution à l'étude écologique et biologıque de la résurgence de Font Estramer et de quelques sources vauclusiennes de la région de Salses-la-Nouvelle. Vie et Milieu, série C, 19 (2-C) : 241 - 286.

LAURENT P.J. et SUSCILLON M., 1962. Les écrevisses de France. Ann. Stat. centr. Hydrob. appl., 9 : 333 - 395.

LAURENT P.J. et FOREST J., 1979. Données sur les écrevisses qu'on peut rencontrer en France. La Pisciculture Franç. 56 : 25 - 40.

LEGER M.L., 1937. Economie biologique générale des cours d'eaux alpins. Trav. Ass. Inter. Limn. théor. et appl., 8 (1) : 5 - 14.

LEGER M.L., 1945. Economie biologique et productivité de nos rivières à cyprinidés. Bull. Fr. Pisc., 139 : $49-69$.

MASUREL Y., 1964. La Provence cristalline et ses envelcppes sédimentaires. Gap. Imp. Louis-Jean : $418 \mathrm{pp}$.

MAUCHA R., 1932. Hydrochemische Methoden in der Limnologie. Stuttgart. Collection Binnengewässer (Publ. A. Thienemann), $12: 173 \mathrm{pp}$

MOLINIER R. et R., 1971. La forêt méditerranéenne en Basse-Provence. Bull. Mus. Hist. Nat. Marseille, $31: 76 \mathrm{pp}$.

REGUIS J.M.F., 1882. Essai sur les vertèbrés de la Provence (Poissons et Batraciens) Marseille : $429 \mathrm{pp}$.

ROL R. et JACAMON M., 1968. Flore des arbres, arbustes et arbrisseaux. Collect. \& La Maison rustique * 3 , Région méditerranéenne, $96 \mathrm{pp}$. 
SPILLMANN C.J., 1961. Poissons d'eau douce. Paris. Faune de France, 65 : 303 pp.

S.R.A.E. (Service Régional de l'Aménagement des Eaux. Aix-en-Provence), 1970. Bassin de l'Argens. Collection * Etudes et ressources hydrologiques et hydrogéologiques Sud-Est de la France, Fasc. 15. (B.R.G.M. - Minist. Agricult. S.R.A.E.).

TUFFERY G. et VERNEAUX J., 1968. Méthodes de détermination de la qualité biologique des eaux courantes. Fascicule Ministère Agricult. Publication C.E.R.A.F.E.R., 21 pp.

VIBERT R., 1967. Importance et caractéristiques essentielles des migrations de reproduction chez les poissons: Bull. Inform. Conseil. Sup. Pêche, $70: 35-43$.

VIVIER P., 1951. Poissons et crustacés d'eau, douce acclimatés en eaux libres depuis le début du siècle. La Terre et la Vie, $98: 57-82$.

VIVIER P., 1952. La vie des eaux douces. Coll. «Que sais-je? *, 233 : 128 pp (1'e édition, 1946).

VIVIER P., 1965. La peste, un facteur de régulation des populations d'écrevisses (Astacus). Mitt. Inter. Verein. Limnol., 13: 49 - 62.

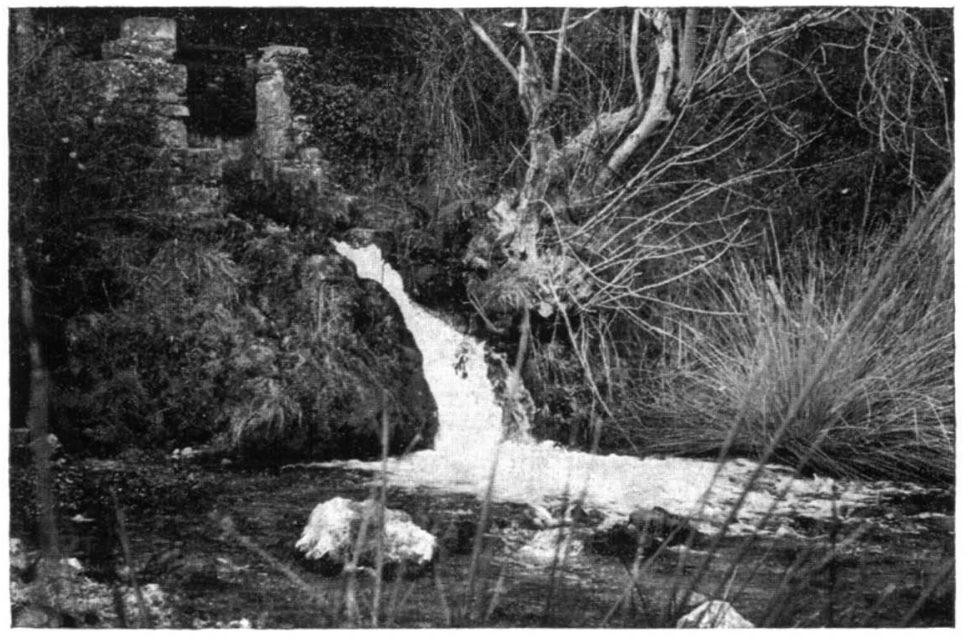

Photo 1 : Zone un peu en aval de la source proprement dite de l'ARGENS. C'est une courte zone de l'épirhithron où le cours d'eau reçoit une partie de ses eaux de la source déviée. 


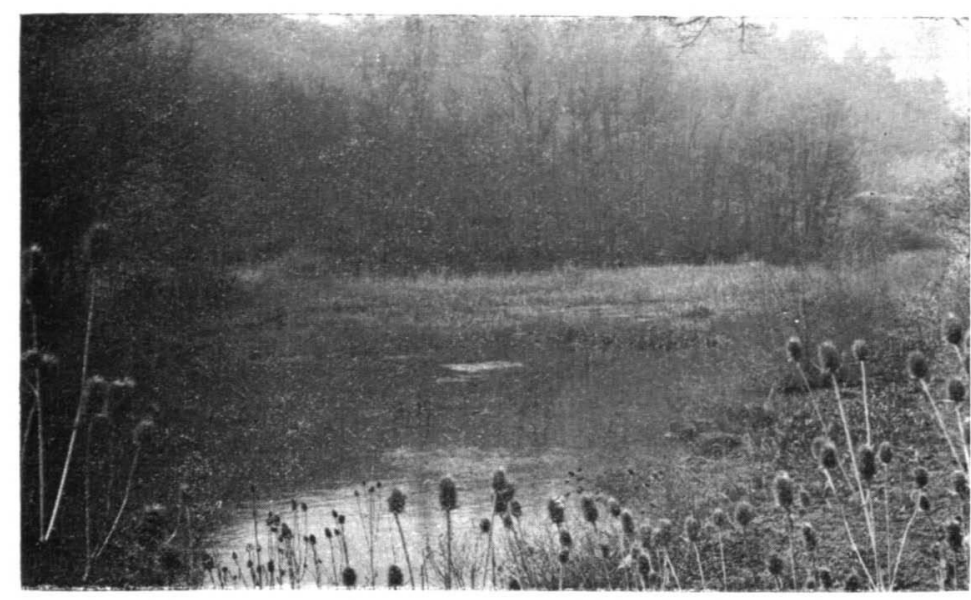

Photo 2 : Zone mixte où le cours d'eau traverse une zone marécageuse. La Fente est faible et la vitesse ce l'eau est très lente. C'est la zone. atypique oủ dominent les cyprinidés.

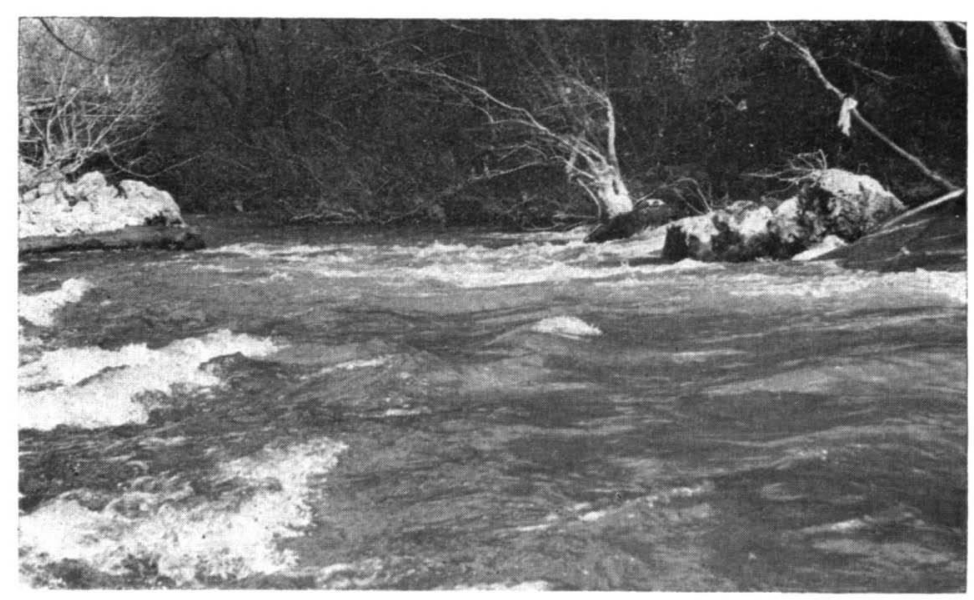

Photo 3 : Après sa ccnfluence avec le CAURON, la pente de l'ARGENS redevient plus forte et c'est une zone typique à truites (Rhithron).

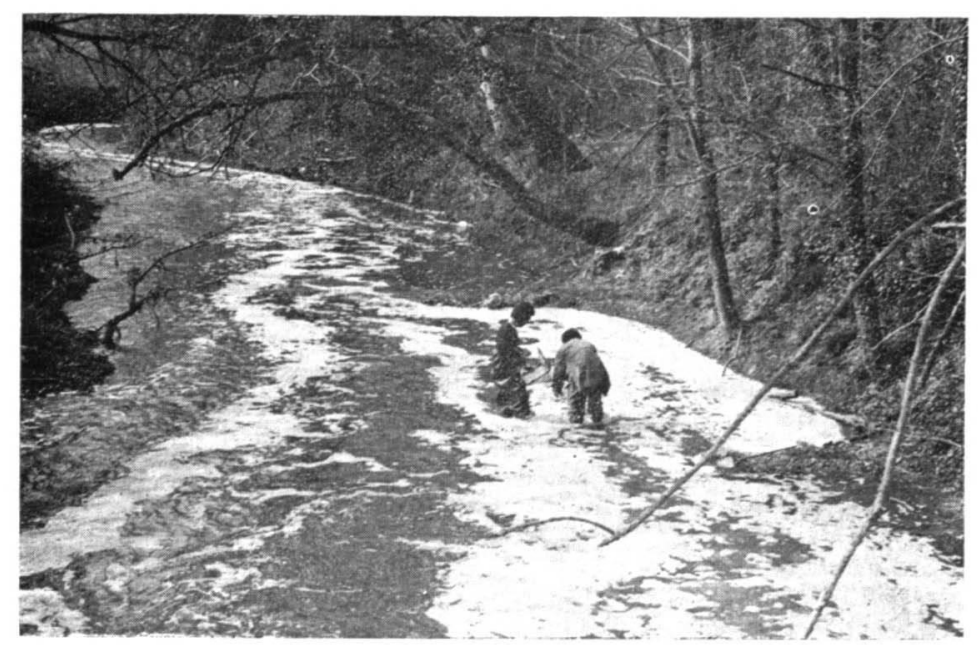

Photo 4 : L'EAU SALEE est un affluent important. Prélèvements hydrobiologiques en vue d'évaluer la pollution et l'influence qu'elle peut avoir sur I'ARGENS proprement dit. 


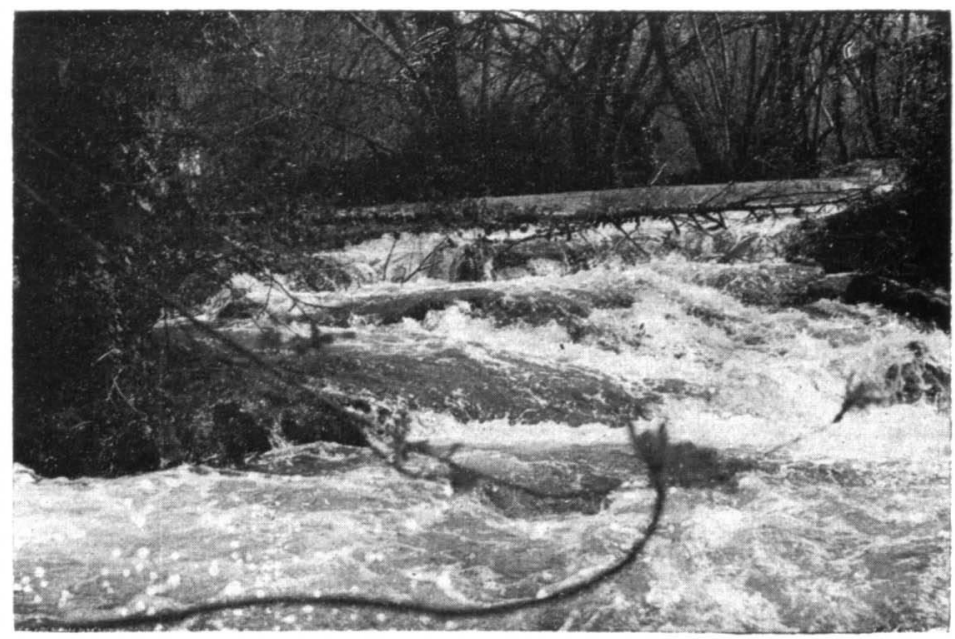

Photo 5 : Rapides à la sortie de la retenue de CARCES.

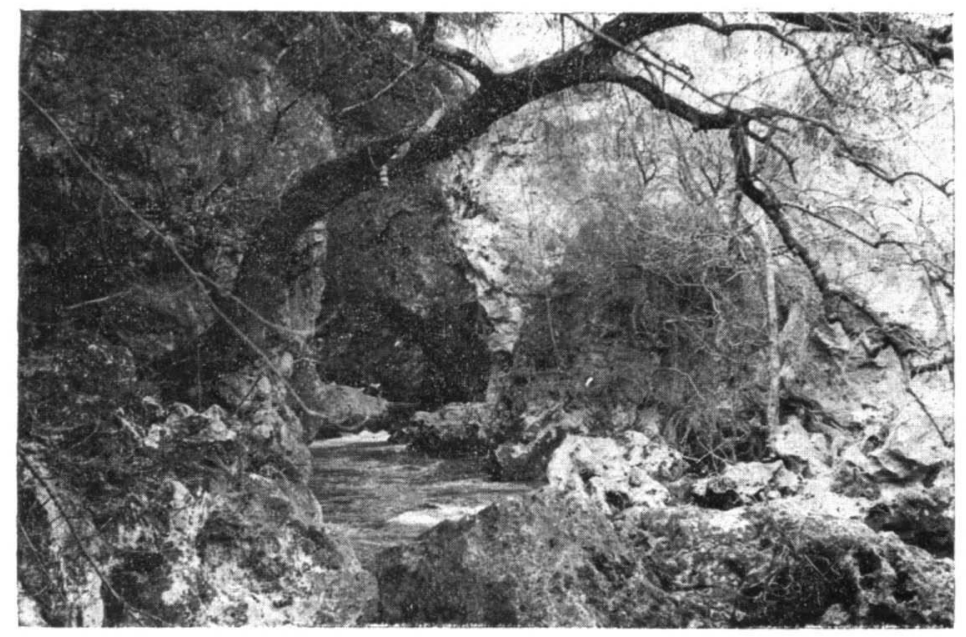

Photo 6 : Couloir karstique après la perte de l'ARGENS (en amont de l'usine EDF d'ENTRAIGUES, près de VIDAUBAN).

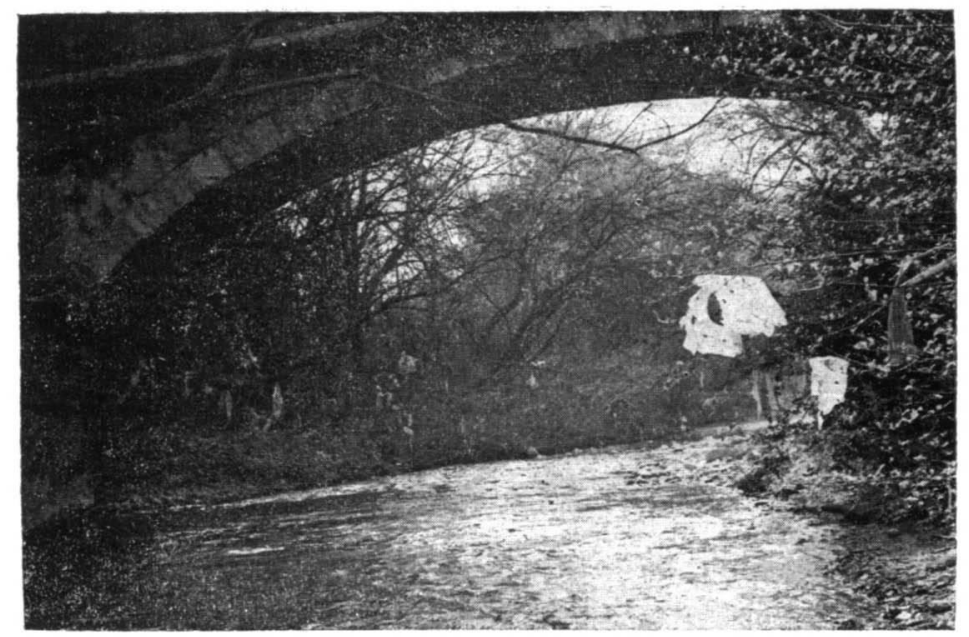

Photo 7 : Pollution de l'ARGENS par des plastiques ! 


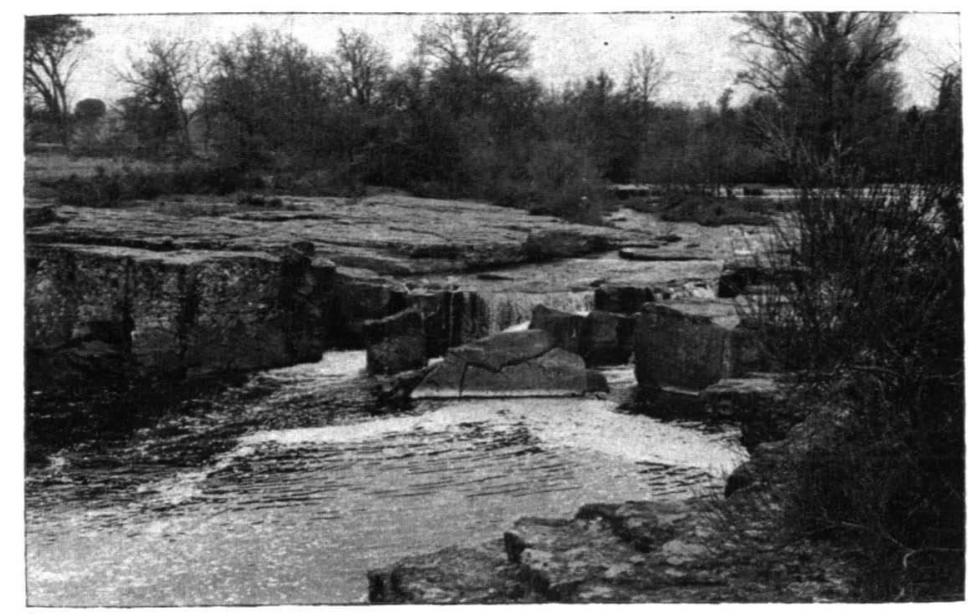

Photo 8 : L'AlLLE est un affluent important. Elle draine une zone de la Provence-cristalline. Petites cascades du moulin' de BOUISSE.

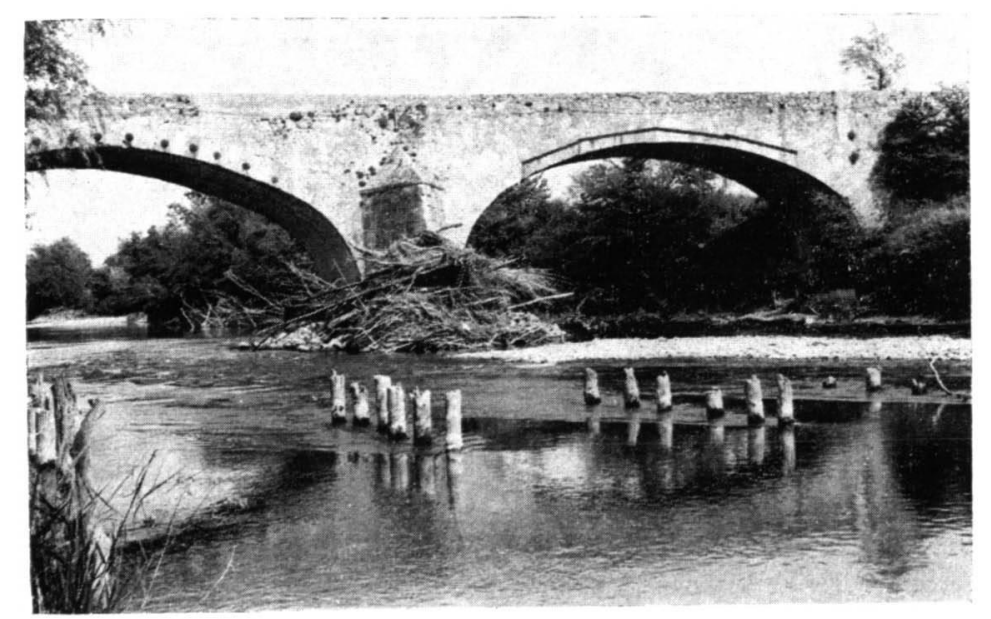

Photo 9 : L.ARGENS à ROQUEBRUNE. II reste, au premier plan, les vestiges de piliers d'un pont de bois provisoire construit pour certains travaux dans la rivière (réparation du vieux Pont médiéval).

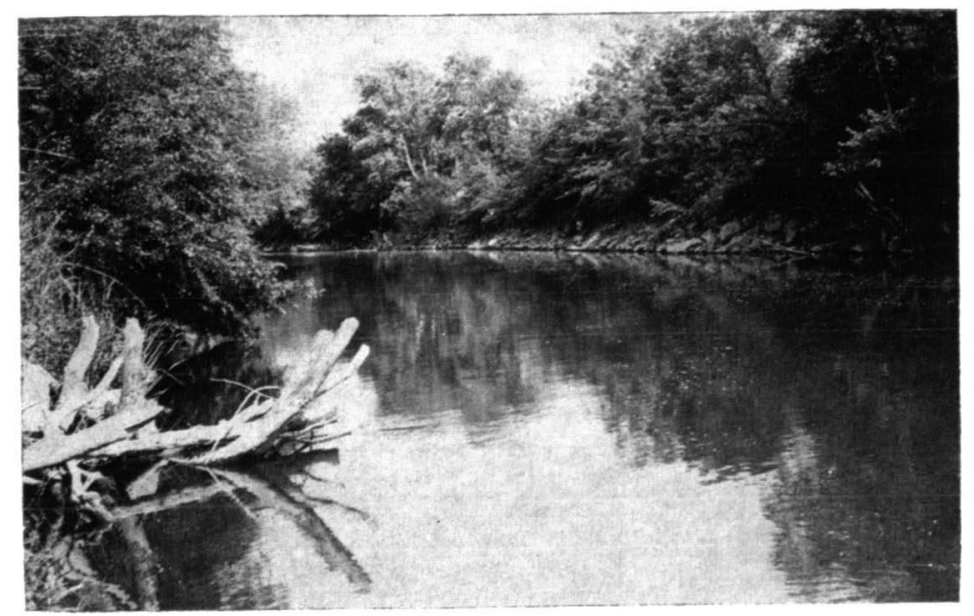

Photo 10 : L'ARGENS en aval de ROQUEBRUNE. C'est une ancienne zone à gravières où les exploitations ont été localisées en dehors du lit. 


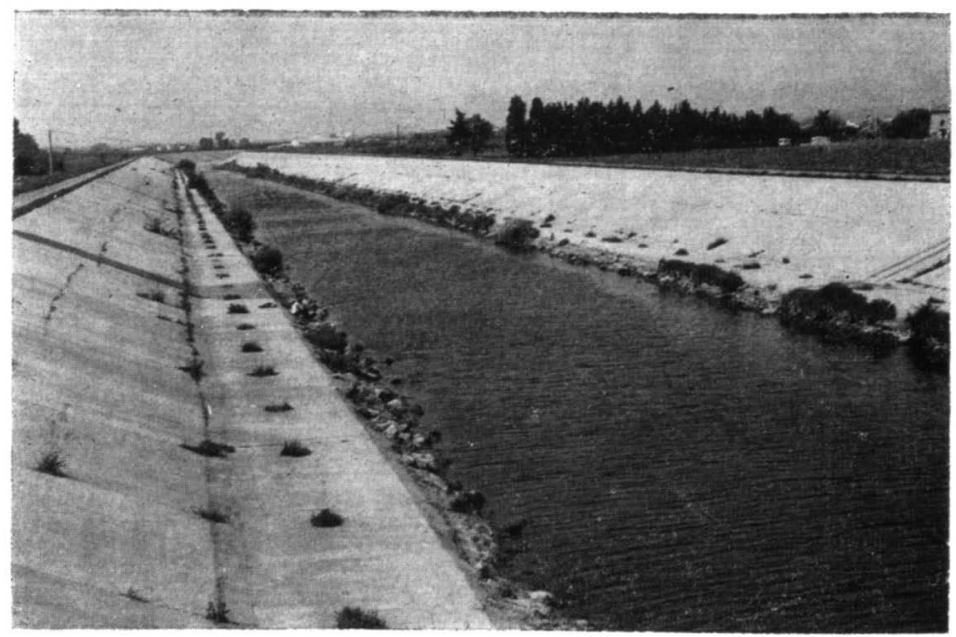

Photo 11 : Le REYRAN, canalisé, se jette dons l'estuaire de l'ARGENS, non loin de l'embouchure.

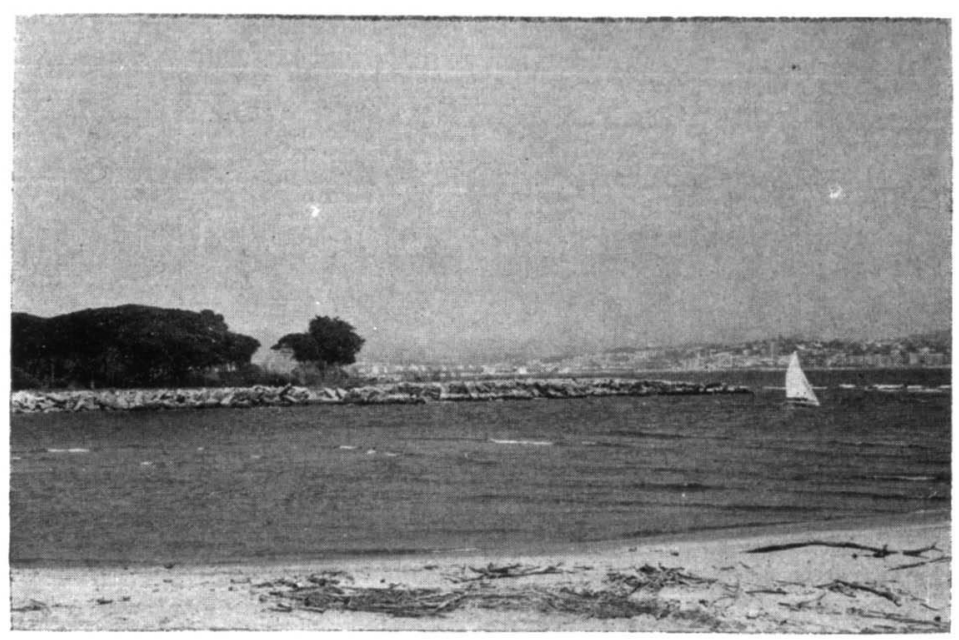

Photo 12 : Embouchure de l'ARGENS et zone noyée de la barre sablonneuse.

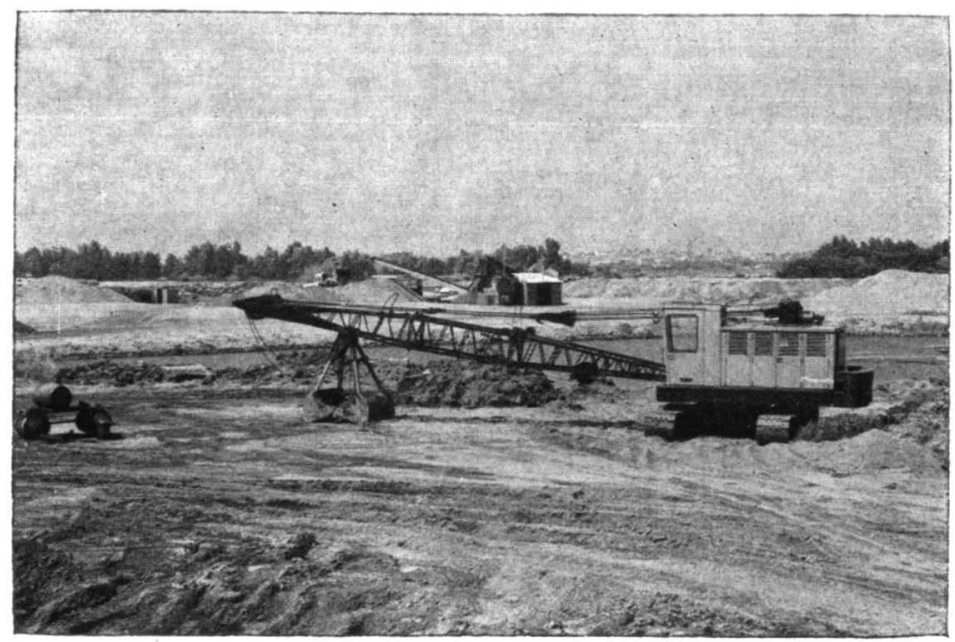

Photo 13 : Exploitations de sable au voisinage Sud de l'embouchure. 